Portland State University

PDXScholar

\title{
Using Thermal Gradient Measurements to Compare Bath Temperature and Agitation Effects on the Quenching Performance of Palm Oil, Canola Oil and a Conventional Petroleum Oil
}

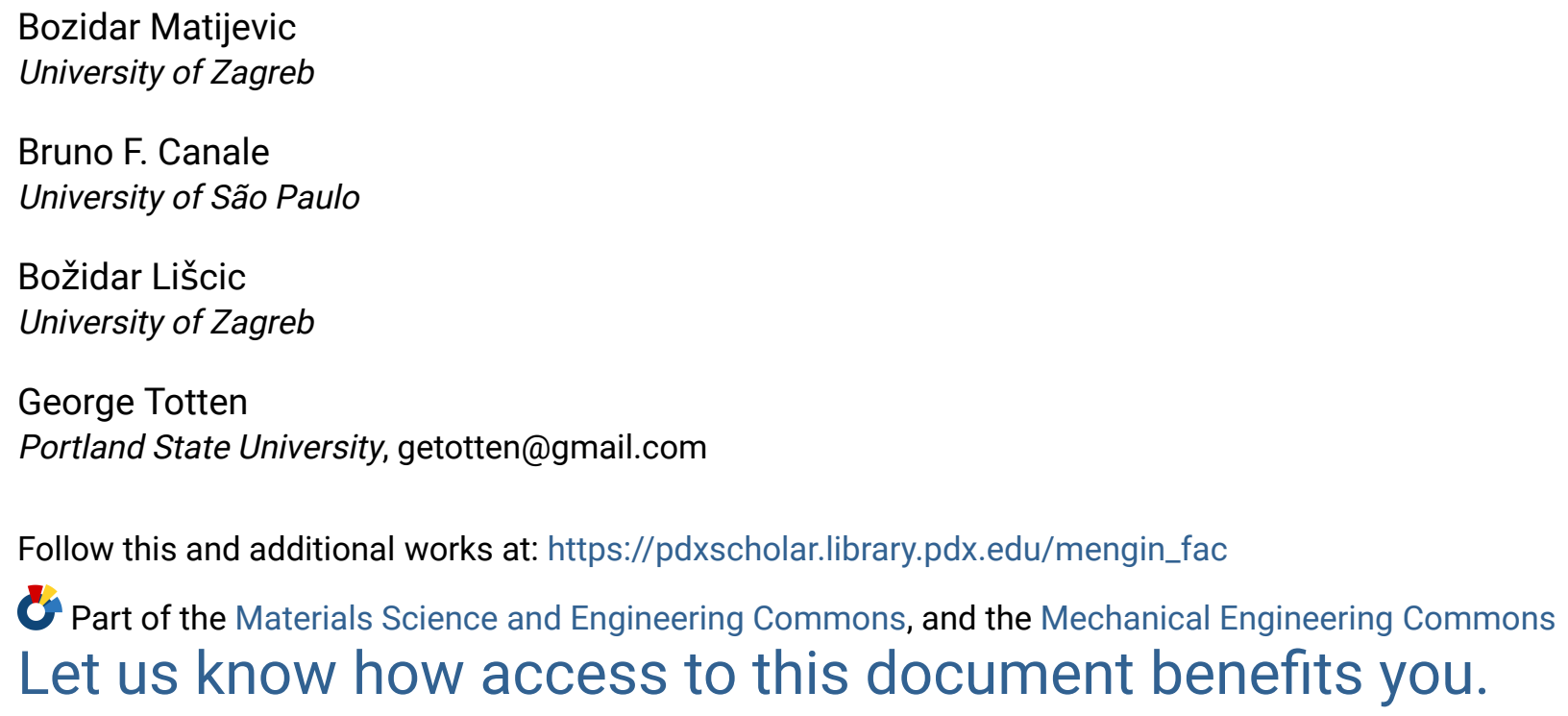

\section{Citation Details}

B. Matijevic, B. F. Canale, B. Liscic, and G. E. Totten, "Using Thermal Gradient Measurements to Compare Bath Temperature and Agitation Effects on the Quenching Performance of Palm Oil, Canola Oil and a Conventional Petroleum Oil," Materials Performance and Characterization 8, no. 1 (2019): 223-248, https://doi.org/10.1520/MPC20180135.

This Article is brought to you for free and open access. It has been accepted for inclusion in Mechanical and Materials Engineering Faculty Publications and Presentations by an authorized administrator of PDXScholar. Please contact us if we can make this document more accessible: pdxscholar@pdx.edu. 
Manuscript received August 15, 2018; accepted for publication April 8, 2019; published online May 23, 2019.

${ }^{1}$ Faculty of Mechanical Engineering and Naval Arch., University of Zagreb, 10000 Zagreb Ivana Lucica 5, Zagreb, Croatia

2 Department of Telecommmunication and Control, University of São Paulo, 380 Av. Prof. Luciano Gualberto Butantã, São Paulo, SP 05508010, Brazil (Corresponding author), e-mail: bruno.canale@ usp.br, (D) https://orcid.org/ 0000-0002-1377-0544

3 Department of Mechanical and Materials Engineering, Portland State University, 1930 SW 4th Ave. Suite 400, Portland, OR 97201, USA, (iD https://orcid.org/ 0000-0002-7313-1437
Bozidar Matijevic, ${ }^{1}$ Bruno F. Canale, ${ }^{2}$ Bozidar Liscic, ${ }^{1}$ and George E. Totten ${ }^{3}$

\section{Using Thermal Gradient Measurements to Compare Bath Temperature and Agitation Effects on the Quenching Performance of Palm Oil, Canola Oil and a Conventional Petroleum Oil}

\section{Reference}

B. Matijevic, B. F. Canale, B. Liscic, and G. E. Totten, “Using Thermal Gradient Measurements to Compare Bath Temperature and Agitation Effects on the Quenching Performance of Palm Oil, Canola Oil and a Conventional Petroleum Oil," Materials Performance and Characterization 8, no. 1 (2019): 223-248, https://doi.org/10.1520/MPC20180135

\section{ABSTRACT}

A proprietary Liscic/Petrofer cylindrical Inconel 600 probe of $50-\mathrm{mm}$ diameter and $200-\mathrm{mm}$ length which was instrumented with three thermocouples on the same radius of the crosssection at the middle of the length was used to determine the differences in quenching performance of two vegetable oils, palm oil and canola oil, and they were compared to a locally produced conventional petroleum oil quenchant. The cooling curves and heat transfer performance of these oils were determined at different bath temperatures and agitation rates. The work was performed at the Quenching Research Centre located at the Faculty for Mechanical Engineering, University of Zagreb, Croatia. The results of this comparative study are reported herein.

\section{Keywords}

quenching intensity, temperature gradient method, heat transfer coefficient, palm oil, canola oil, petroleum oil

\section{Introduction}

Cooling characteristics of a liquid quenchant are usually determined by cooling curve analysis using a laboratory test such as ISO 9950, Industrial Quenching Oils Determination of Cooling Characteristics - Nickel-Alloy Probe Test Method, or ASTM D6200, Standard Test Method for Determination of Cooling Characteristics of Quench 
Oils by Cooling Curve Analysis, ${ }^{1}$ standards, which utilize a small cylindrical test probe of $12.5 \mathrm{~mm}$ diameter by 60 $\mathrm{mm}$ length with one thermocouple (TC) at its geometrical center. These tests are invaluable for the characterization and selection of a relatively small volume $(\leq 2 \mathrm{~L})$ of a quenching fluid or for the regular monitoring of a quenching bath under laboratory testing. However, the use of such small test probes is of limited value for the measurement and recording of the real quenching intensity of a fluid when quenching actual components, which are typically much larger, under workshop conditions. Relatively small probes such as the $12.5 \mathrm{~mm}$ diameter by 60-mm length probe used in ASTM D6200 are unable to provide time-temperature cooling data for the modeling and simulation of quenching real workpieces for the following reasons:

- Because of its relatively small mass and low heat capacity, these smaller probes will cool within approximately 10 to 30 seconds, whereas an actual ("real") workpiece with a 50-mm diameter requires 500 to 600 seconds to cool to below $200^{\circ} \mathrm{C}$ at its center when quenched into unagitated quench oil.

- The heat transfer coefficient (HTC) during nucleate boiling is dependent on bar diameter. ${ }^{2}$ This dependence is particularly significant for diameters below $50 \mathrm{~mm}$. Therefore, for the same quenching conditions, the HTC on the surface of a small-diameter cylinder is quite different from the HTC on the surface of real workpieces, which are typically much larger.

- For other quenching parameters, such as the quenchant bath temperature, agitation rate, and flow direction, arrangement of workpieces in a batch (racking) are completely different from that of a laboratory test with a small test probe used under unagitated conditions.

To address the limitations of the use of small probes such as that specified in ASTM D6200, the Liscic/Petrofer probe was designed to measure and record the cooling intensity of all types of liquid quenchants using different quenching techniques, including immersion quenching, intensive quenching, delayed quenching, martempering, and austempering to characterize quenching processes in industrial practice and for comparing their quenching intensity. ${ }^{3}$

The Liscic/Petrofer probe is a solid cylinder of $50-\mathrm{mm}$ diameter and $200-\mathrm{mm}$ length. Figure $1 A$ is the schematic of the probe with the handle and figure $1 B$ is a photo of the probe itself. The ratio between the length and diameter $L / D=4: 1$ ensures that the heat dissipation effect through both ends of the probe is negligible so that in the cross-section at the half-length of the probe where the TCs are positioned, only radial heat flow exists. This is a prerequisite for

FIG. 1

(A) Sketch of the Liscic/ Petrofer probe with the handle; $(B)$ photo of the Liscic/Petrofer probe.

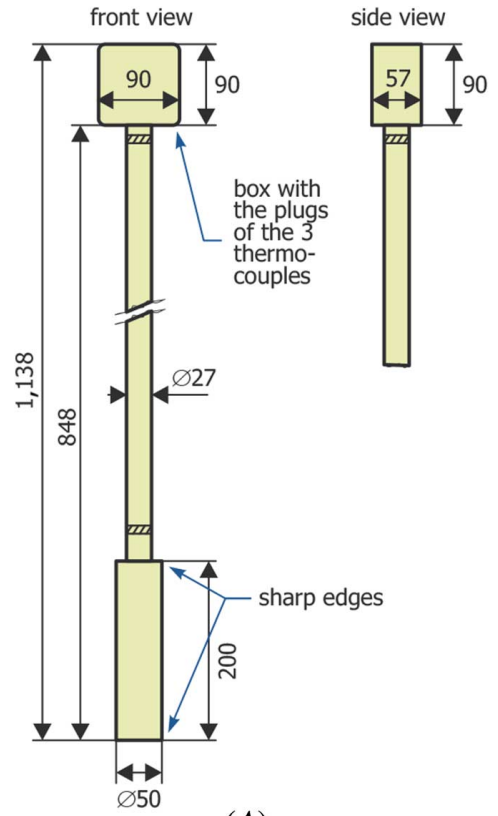

(A)

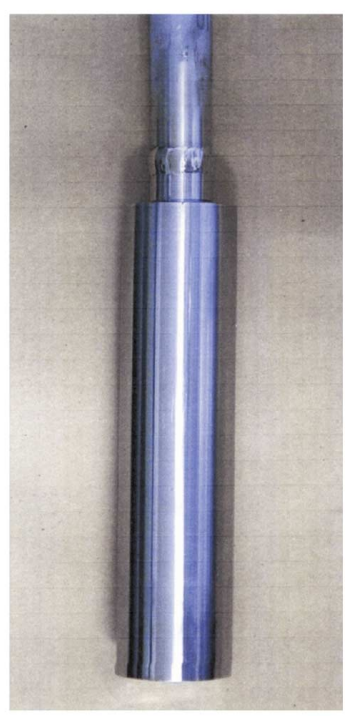

$(B)$ 
one-dimensional (1-D) heat transfer calculations. Because of its cylindrical shape, the Liscic/Petrofer probe is applicable for heat transfer calculations of axially symmetric workpieces with diameters between 20 and $100 \mathrm{~mm} .^{3}$

The Liscic/Petrofer probe is constructed of Inconel 600, a nickel-chromium austenitic alloy, which, during heating and cooling, does not undergo structural transformation and is oxidation resistant. The probe is instrumented with three sheathed and grounded TCs: one placed $1 \mathrm{~mm}$ below the surface, the second one $4.5 \mathrm{~mm}$ below the surface, and the third at the center of the cross-section at the half-length of the probe.

In the Liscic/Petrofer probe illustrated in figure 1, all TCs are placed along the same radius at one-half the length. The size of the probe and its mass ( $3.3 \mathrm{~kg}$ without handle) ensures sufficient heat capacity and radially symmetric heat flow in the cross-sectional plane where the TCs are located. By placing the outer TC (the measured data of which are used as input for heat transfer calculations) at $1 \mathrm{~mm}$ below the surface, minimum damping effect of transient surface temperature is assured. Also, the lagging effect (because of thermal diffusivity) is minimized, because of the small distance to the surface. The response time (which depends on the outer diameter of the TC) is relatively short because the diameter of the TC at $1 \mathrm{~mm}$ below the surface is only $1 \mathrm{~mm}$.

A comparison of the advantages of the use of the Liscic/Petrofer probe relative to the $12.5 \mathrm{~mm}$ diameter by 60-mm length ASTM D6200 probe is summarized in Table $1 .{ }^{4}$

There is currently a renewed interest in identifying renewable alternatives to petroleum oil as quenchants for steel. ${ }^{5}$ This study was conducted to address the suitability of potential replacement of a commercial petroleumderived quenchant with a vegetable oil. Palm oil and canola oil, two widely available vegetable oils potentially suitable for industrial quenchant formulation, were selected. Palm oil is the most consumed vegetable oil in the world. With a production rate of 62 million tons annually, palm oil represents $38 \%$ of the world production of vegetable oil while occupying less than $10 \%$ of the surface of vegetable oil crops. Although palm oil is produced by various countries internationally, including Brazil, Indonesia and Malaysia are the main producers, providing $85 \%$ of palm oil between them. ${ }^{6}$ However, it is important to understand that, as with other agriculturally produced seed oils, the triglyceride structure and resulting physical characteristics of palm oil are variable depending on geographical location, cultivar, agronomic practice, and production method. ${ }^{7}$ It has been reported that the geographical origin of crude palm oil is feasible by fatty acid and volatile compound fingerprinting. ${ }^{8}$

Canola oil, a low-erucic acid rapeseed oil, was also selected for this study to provide a relative performance characterization with respect to palm oil. Canola oil was developed after significant improvement and modification of the original high-erucic acid rapeseed oil. ${ }^{9}$ Canada is the world's largest producer and exporter of canola oil. More than 43,000 Canadian farmers produced 18 million tons of canola (a $29 \%$ increase in yield), providing a $\$ 19.3$ billion industry for the country in 2013, with the largest producing region being Saskatchewan, followed by Alberta and Manitoba. ${ }^{10}$ Canada exports around 800,000 tons of canola oil annually with the largest importer being the United States, with small quantities going to Mexico, China, and Europe. ${ }^{10}$ As with palm oil and other seed oils, both the season of the year and origin of the plant will affect the chemical composition. ${ }^{11}$

Recently, the relative quenching performance of an extensive series of vegetable oils has been studied, using the standard ISO 9950/ASTM D6200 $12.5 \mathrm{~mm}$ diameter by 60-mm length cylindrical Inconel 600 probe with a single TC inserted to the geometric center. ${ }^{12}$ In addition to extensive cooling curve time-temperature behavior of these quenchants, heat transfer characteristics were quantified using this probe as well. ${ }^{13}$

For industrial quenchant formulation, vegetable oils require the addition of an antioxidant. ${ }^{14}$ Of the various vegetable oils that have been evaluated as potential quenchants, palm oil was reported to be the most stable to thermal-oxidative degradation. ${ }^{15}$ This was attributable to the substantially lower polyunsaturated triglyceride components in the chemical composition of the oil. The comparative quenching behavior of palm oil was not included in earlier de Souza studies ${ }^{12,13}$ but was subsequently performed by Belinato, Canale, and Totten ${ }^{15}$ and Said et al. ${ }^{16}$ Recently, extensive heat transfer characterization of palm oil and coconut oil versus a petroleum oil was reported by Kobasko et al., who used the small 12.5 -mm diameter multiple-TC probe for this work. ${ }^{17}$

Until now, most of the recent published work characterizing the quenching performance of vegetable oils has been performed with the small 12.5-mm diameter Inconel 600 probes described in ISO 9950 and ASTM D6200. These studies have provided only limited information regarding the effect of bath temperature and agitation, and none of the 
TABLE 1

Summary of differences between the small ASTM D6200 Inconel 600 probe and the larger Liscic/Petrofer Inconel probe

\begin{tabular}{ll} 
& ASTM D6200 $12.5 \mathrm{~mm}$ diameter by \\
$60-\mathrm{mm}$ length Cylindrical Inconel 600 & \\
Item No. & Probe (Center Thermocouple Only) \\
\hline 1. & $\begin{array}{l}\text { Impossible to investigate self-regulated } \\
\text { thermal process }\end{array}$
\end{tabular}

2. Because of the small diameter, the initial heat flux density during immersion of the Inconel 600 probe into cold liquid is almost four times larger compared to the Liscic/Petrofer probe, resulting in different types of film boiling.

3. It is impossible to accurately investigate initial processes occurring during immersion of steel parts into liquid quenchant.

4. Many companies provide cooling curves and cooling rates of standard probe obtained during its testing of their liquid quenchants. However, such data do not relate to quenching of actual parts in the heat-treat shop.

5. Because of the simple approach in acquiring cooling curves and cooling rates, customers save time and money when using standard Inconel 600 probe.

6. It is impossible to investigate fundamental initial processes during quenching of steel parts heated to high temperatures.

7. There are currently several thousands of small standard Inconel 600 probes in use throughout the world.

8. The standard Inconel 600 probe (12.5 $\mathrm{mm}$ in diameter and $60 \mathrm{~mm}$ long) is useful for laboratory tests of different oils or polymer solutions to compare their cooling ability when testing a new delivery or developing a new quenchant and for monitoring of the deterioration of a quenching bath.

9. No information on temperature field through the section of a probe

Liscic/Petrofer Cylindrical Inconel 600

Probe (50 mm Diameter by $200 \mathrm{~mm}$ Multiple Thermocouple Probe)

Comments

The Liscic/Petrofer probe with three TCs provides accurate surface temperature behavior during boiling processes.

In many cases, the film boiling that is necessary for generalization of experimental data is absent.

Provides initial temperature gradients during probe immersion into the liquid quenchant

On average, it provides realistic data occurring during quenching in liquid quenchants.

Because of a more complicated approach, when testing with the Liscic/ Petrofer probe, results in increased testing expense

It is possible to investigate fundamental initial processes during immersion of steel parts into liquid quenchants.

Currently, there is only one company which has the Liscic/ Petrofer probe and uses it for their own experiments.

The experimental data obtained by Liscic/Petrofer probe more closely approximate industrial processes.

Ability to measure and record the quenching intensity of different liquid quenching media (including molten saltbaths), under different quenching conditions and with different quenching techniques (conventional quenching, intensive quenching, delayed quenching, martempering, and austempering)
The Liscic/Petrofer probe allows determining both real and effective HTCs. The Inconel 600 probe provides only effective HTCs for small diameter. Film boiling, especially local film boiling, is undesirable, since it leads to increased distortion and nonuniform surface hardness.

The initial phase of cooling in liquid quenchants is the most important, since it dictates the future history of cooling.

Using Liscic/Petrofer probes, it is possible to modify the correlation between the duration of transient nucleate boiling process and size, form, and thermal properties of solid material and liquid.

In fact, customers are not utilizing all process capabilities of their quench system when using data from a smaller probe, which may result in increased cost due to decreased effectiveness.

Fourier's classical law of heat conductivity doesn't work properly during immersion of high-temperature steel parts into liquid quenchants. Unfortunately, it is impossible to investigate self-regulated thermal processes using a standard Inconel 600 probe.

The small-diameter probe generates film boiling more easily because of higher initial heat flux density. As a result, the heat extraction dynamic from this small probe (surface heat flux) is totally different from those obtained when quenching actual parts.

The Inconel 600 probe cannot be used for investigating martempering and austempering processes. 
prior studies addressed bath temperature and agitation effects of vegetable oil performance on heat transfer. The objective of this work was to examine the thermal gradients produced in larger cross-sections by canola oil, the most common vegetable oil used for industrial oil formulation in North America, and palm oil versus a conventional commercial petroleum oil quenchant using the Liscic/Petrofer probe with varying agitation and bath temperature. ${ }^{3}$ This study is a continuation of earlier work reported for these quenching media using the Liscic/Petrofer probe but without considering the effects of agitation and bath temperature. ${ }^{18}$ The results of this continued work are reported here.

\section{Experimental}

\section{TEST PROCEDURE}

This study involves the examination of the effect of agitation on quenching performance. Therefore, the use of a standardized agitation system would be desirable, if available. Although there are two standardized agitation systems, ASTM D6549, Standard Test Method for Determination of Cooling Characteristics of Quenchants by Cooling Curve Analysis with Agitation (Drayton Unit), ${ }^{19}$ and ASTM D6746, Standard Test Method for Determination of Cooling Characteristics of Quenchants by Cooling Curve Analysis with Agitation (Tensi Method), ${ }^{20}$ these systems were developed for a much smaller $12.5 \mathrm{~mm}$ diameter by 60 - $\mathrm{mm}$ length cylindrical Inconel 600 probe and because of the relatively limited size and fluid volume are inappropriate for use in this study. As a result, a much larger quenchant agitation system is necessary that is suitable to appropriately accommodate the $50 \mathrm{~mm}$ diameter and

FIG. 2

Schematic illustration of the quench system depicted in figure 3 to illustrate the fluid agitation system.

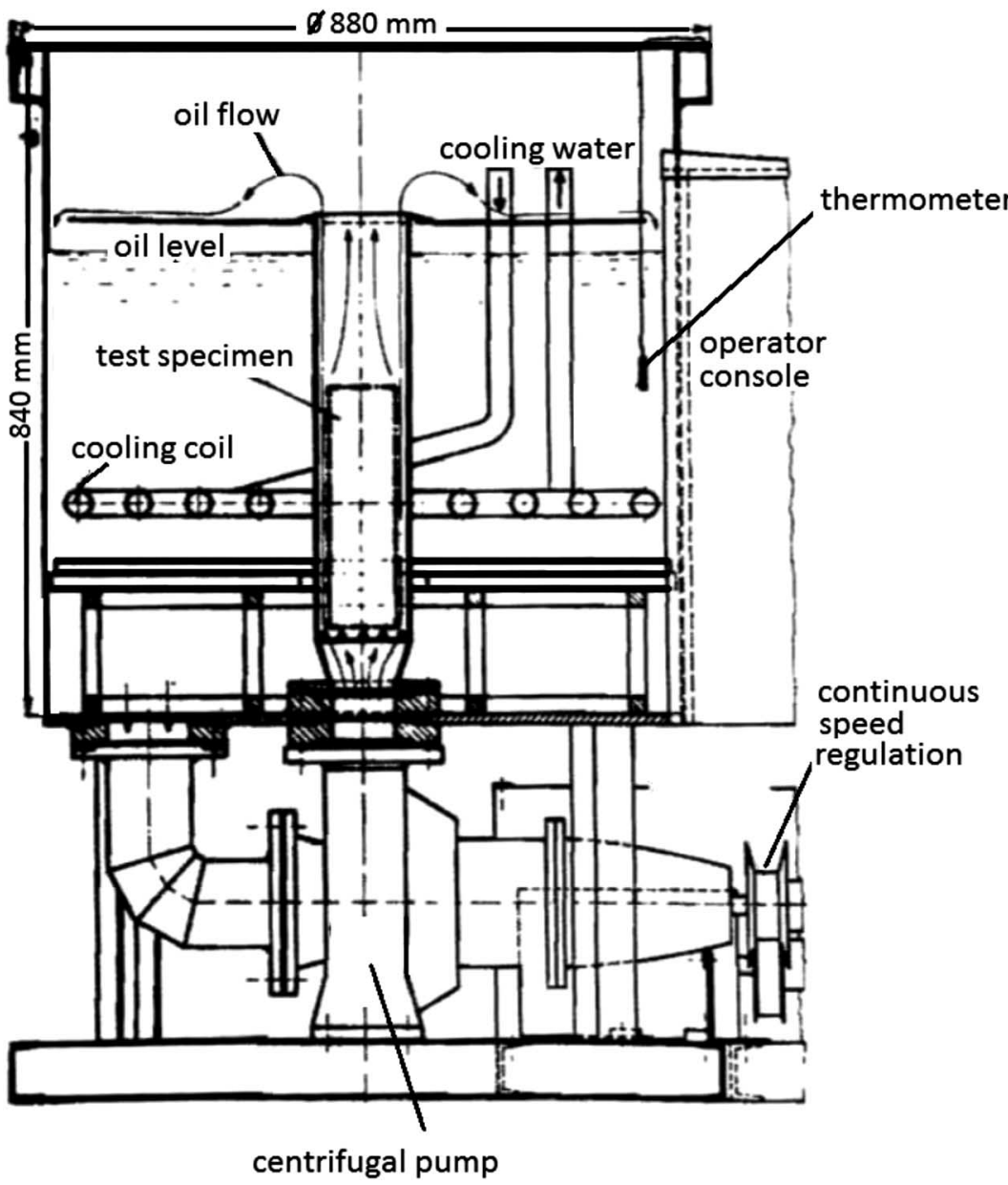


$200 \mathrm{~mm}$ Inconel $600 \mathrm{Liscic} /$ Petrofer probe described previously. To provide the necessary and adequate agitation required for the Liscic/Petrofer probe used in this study, an agitation system first described in a 1978 publication ${ }^{18}$ was used for this study and is illustrated in figure 2. Details of this agitation system will be provided subsequently.

The test procedure is as follows: the probe is heated to $850^{\circ} \mathrm{C}$ until the central TC reaches this value, then it is quickly transferred to the quenching bath and immersed vertically into $300 \mathrm{~L}$ of quench oil in the quenching system pictured in figure 3. It is of the utmost importance that the transfer from the furnace to the quenching bath is always performed within the same short period of time, as well as immersing the probe with the same speed, strictly vertically, to provide equivalent cooling conditions around the perimeter of the probe. Vertical transfer is assured by the use of a jig for probe transfer above the quench system, as shown in figure 3.

The probe is connected to a temperature data acquisition system that contains three analog-to-digital converters and amplifiers and a personal computer. The data acquisition software enables the recording of all $3 \mathrm{TC}$ signal outputs with a frequency of $0.02 \mathrm{~s}$ (50 measurements per second) during the entire quenching process and simultaneously drawing the 3 resulting cooling curves in real time. The resulting cooling curves obtained are provided in the Appendix.

\section{MATERIALS}

To the palm and canola oil (provided by INA Maziva in Zagreb, Croatia) used for this work, $0.5 \%$ by weight of propyl gallate (obtained from Sigma-Aldrich), an antioxidant, was added. The physical properties of both vegetable oils before antioxidant addition are summarized in Table 2 and those for the commercial petroleum oil (Kalenol 32, provided by INA Maziva in Zagreb, Croatia) are shown in Table 3.

The quench rig is equipped with an agitation system that is depicted schematically in figure 2 . This agitation system provides vertical flow from the bottom to the top at flow velocities between 0 and $1.0 \mathrm{~m} / \mathrm{s}$ controlled by the pump (Egger T4-80) rotation. In this system, an agitation rate of $500 \mathrm{r} / \mathrm{min}$ is considered to be moderate and has been measured as $0.5 \mathrm{~m} / \mathrm{s}$, and an agitation rate of $800 \mathrm{r} / \mathrm{min}$ is considered to be intensive agitation and has been measured as $0.8 \mathrm{~m} / \mathrm{s}$.

\section{COOLING CURVE AND HEAT TRANSFER DATA ANALYSIS}

\section{Temperature Gradient Method}

The main feature, when comparing the quenching intensity among different quenching processes, is the ability to extract heat from a heated workpiece, i.e., the dynamic of heat extraction. This implies that the real quenching intensity in workshop practice cannot be estimated by a single number only (as is the case with Grossmann's $\mathrm{H}$-value), and neither can it be measured and recorded by the small test specimen used for laboratory tests.

TABLE 2

Summary of physical properties of palm oil and canola oils before antioxidant addition

\begin{tabular}{|c|c|c|c|}
\hline Property & Canola Oil & Palm Oil & Test Method \\
\hline Viscosity, $40^{\circ} \mathrm{C}, \mathrm{mm}^{2} / \mathrm{s}$ & 35.14 & 40.39 & ISO 3104 \\
\hline Viscosity, $100^{\circ} \mathrm{C}, \mathrm{mm}^{2} / \mathrm{s}$ & 8.7 & 8.53 & ISO 3104 \\
\hline Viscosity index & 198 & 136 & ISO 2909 \\
\hline Density $15^{\circ} \mathrm{C} / 20^{\circ} \mathrm{C}, \mathrm{g} / \mathrm{mL}$ & $0.9201 / 0.9170$ & $0.9151 / 0.9119$ & ASTM D4052 \\
\hline Open cup flash point, ${ }^{\circ} \mathrm{C}$ & 300 & 326 & ISO 2592 \\
\hline Pour point, ${ }^{\circ} \mathrm{C}$ & -24 & +6 & ISO 3016 \\
\hline Acid number, $\mathrm{mg} \mathrm{KOH} / \mathrm{g}$ & 0.10 & 0.18 & ISO 6618 \\
\hline Saponification number, mg potassium hydroxide $(\mathrm{KOH}) / \mathrm{g}$ & 190.8 & 197.3 & ISO 6293 \\
\hline
\end{tabular}

Note: ISO 3104:1994 - Petroleum Products - Transparent and Opaque Liquids - Determination of Kinematic Viscosity and Calculation of Dynamic Viscosity; ISO 2909:2002 - Petroleum Products - Calculation of Viscosity Index from Kinematic Viscosity; ASTM D4052-18a - Standard Test Method for Density, Relative Density, and API Gravity of Liquids by Digital Density Meter; ISO 2592:2017 - Petroleum and Related Products - Determination of Flash and Fire Points - Cleveland Open Cup Method; ISO 3016:1994 - Petroleum Products - Determination of Pour Point; ISO 6618:1997 - Petroleum Products and Lubricants - Determination of Acid or Base Number - Colour-Indicator Titration Method; ISO 6293-2:1998 - Petroleum Products and Lubricants - Determination of Acid or Base Number - Colour-Indicator Titration Method. KOH=potassium hydroxide. 
TABLE 3

Properties of Kalenol 32

\begin{tabular}{lcr}
\hline Property & Value & Test Method \\
\hline Viscosity, $40^{\circ} \mathrm{C}, \mathrm{mm}^{2} / \mathrm{s}$ & 32 & ISO 3104 \\
Viscosity, $100^{\circ} \mathrm{C}, \mathrm{mm}^{2} / \mathrm{s}$ & 5.4 & ISO 3104 \\
Viscosity index & 100 & ISO 2909 \\
Density $15^{\circ} \mathrm{C}, \mathrm{g} / \mathrm{mL}$ & 0.863 & ASTM D4052 \\
Open cup flash point, ${ }^{\circ} \mathrm{C}$ & 225 & ISO 2592 \\
Pour point, ${ }^{\circ} \mathrm{C}$ & -15 & ISO 3016 \\
\hline
\end{tabular}

FIG. 3

$(A, B)$ Photograph of the quenching system used for this work; (C) illustration of the jig used to ensure vertical transfer into the same location and depth of the probe into the tank; $(D)$ the cooling system.

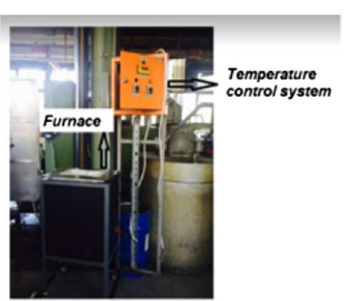

(A)

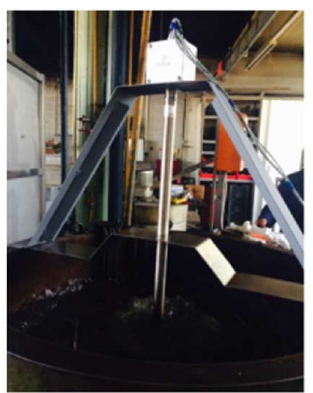

(C)

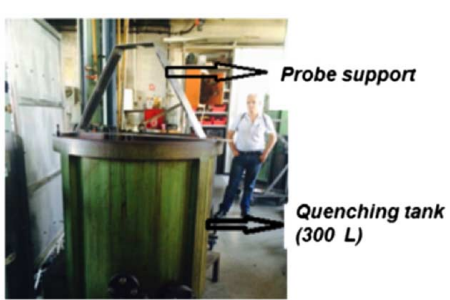

(B)

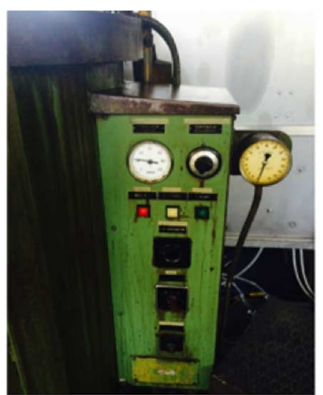

(D)

Physically the most correct way to measure and record the heat extraction dynamic during quenching is by the heat flux density $\left(\mathrm{W} / \mathrm{m}^{2}\right)$ on the surface of the quenched workpiece, from which the HTC is calculated. The heat flux density $(q)$ on the workpiece surface is inherently connected with the changing temperature gradients inside the workpiece, since the heat flux on the surface of a body is directly proportional to the temperature gradient at the surface multiplied by the thermal conductivity of the material of the body being cooled. See the following:

$$
q=\lambda \times \frac{\partial T}{\partial x}
$$

where $q$ is the heat flux density $\left(\mathrm{W} / \mathrm{m}^{2}\right)$, i.e., the quantity of heat transferred through a surface unit per unit of time; $\lambda$ is the thermal conductivity of the body material $(\mathrm{W} / \mathrm{mK})$; and $\frac{\partial T}{\partial x}$ is the temperature gradient inside the body perpendicular to the surface $(\mathrm{K} / \mathrm{m})$.

When measuring the quenching intensity by a multi-TC probe, the change of the heat flux inside the probe at point of time can be determined as the temperature difference $(\Delta T)$ between the points where the TCs are placed. This method is known in literature as the temperature gradient method. 


\section{Calculation of the HTC When Using the Liscic/Petrofer Probe}

Quenching processes performed in vaporizable liquids are a complex thermodynamic and fluid-dynamic problem, described in Mayinger et al., ${ }^{2}$ encompassing different boiling phases (vapor film, nucleate boiling, and convection). To describe the heat transfer from a heated metallic workpiece to the quenchant, determination of the temperature-dependent HTC is used. To calculate the HTC, a cooling curve measured near the surface of the probe is necessary.

In this case, the probe is considered as a long radially symmetric body of a given radius " $r$." In a simplified 1-D model, the temperature distribution $T(x, t)$ inside the cylinder, for times $t>0$, depends on the radial distance $x(0, r)$ from the center of the cylinder and is determined by the 1-D heat conduction equation:

$$
\rho c \frac{\partial T}{\partial t}=\operatorname{div}(\lambda \operatorname{grad} T)
$$

All the physical properties, $\rho$ (density), $c$ (specific heat capacity), and $\lambda$ (heat conductivity), of the probe material are temperature dependent, so the entire problem is nonlinear. The initial condition $T(x, 0)$ is known (measured), and the problem is to determine the surface HTC, designated " $\alpha$ " in the boundary condition for $x=r$. See the following:

$$
\lambda \frac{\partial T}{\partial x}=\alpha\left(T-T_{\operatorname{ex}(t)}\right)
$$

where $T_{\mathrm{ex}(t)}$ is the measured external temperature of the quenchant. To determine $\alpha$, an additional cooling curve $T(t)$ is measured at a point $x=r_{1}$ near the surface (in this case $1 \mathrm{~mm}$ below the surface).

The inverse problem of computation $\alpha$ is solved by the following numerical procedure:

1. Solve the heat conduction equation (2) within the range $\left(0, r_{1}\right)$ with measured $T(t)$, the Dirichlet boundary condition.

2. If $r_{1}<r$, extend the solution toward the boundary from $\left(0, r_{1}\right)$ to $(0, r)$, and

3. Calculate $\alpha$ from equation (3) with measured $T_{\mathrm{ex}(t)}$ by using numerical differentiation.

Since temperatures are measured at discrete times, they must be smoothed before use. This is done by a cubic spline least-squares approximation to obtain a sufficiently smooth global approximation over the entire time range.

Numerical solution of the heat conduction equation (2) is performed by the nonlinear implicit method with a simple iteration per time step to adjust all physical properties to the new temperatures.

The solution extension in Step 2 is computed by local extrapolation based on a low degree polynomial leastsquares approximation. The same approximation is also used for the numerical differentiation needed to compute $\alpha$ in Step 3.

How realistic and exact the determination of the HTC will be also depends on the input data from the point at which the temperature inside the probe is measured.

\section{Distinctive Characteristics of Cooling Curves and Calculated Heat Transfer Data}

When performing tests using the Liscic/Petrofer probe, the results are presented by the following four diagrams:

(a) The recorded cooling curves;

(b) The calculated HTC as a function of time;

(c) The calculated HTC as a function of surface temperature; and

(d) The calculated surface temperatures for canola oil, palm oil, and a conventional commercially available petroleum oil (Kalenol 32) are calculated.

The related curves indicated by (a)-(d) are provided in the Appendix for each of the quenchants and quenching conditions evaluated. In order to impartially analyze and use the experimental results, the following characteristic criteria from those diagrams are applied: 
1. $\Delta T_{10}$ Temperature gradient between the center and the point $1 \mathrm{~mm}$ below the surface at $10 \mathrm{~s}$ after immersion;

2. $t_{\alpha \max }$ Time from immersion to the moment when $\alpha_{\max }$ occurs;

3. $\Delta T_{\max }$ Maximum temperature gradient;

4. $\alpha_{\max }$ Maximum value of the HTC;

5. $T_{\alpha \max }$ Temperature at which $\alpha_{\max }$ occurs; and

6. $\Delta T_{100}$ Temperature gradient between the center and the point $1 \mathrm{~mm}$ below the surface at $100 \mathrm{~s}$ after immersion.

For quenchants with a clearly distinguishable film boiling phase, the transition point between the film boiling and nucleate boiling (the second critical heat flux density $q_{\mathrm{cr} 2}$ ) can be detected.

The most important feature of each quenching process is the dynamic of heat extraction, which is best represented by the change of temperature gradients. The earlier specified criteria include the following 3 temperature gradients: $\Delta T_{10}, \Delta T_{\max }$, and $\Delta T_{100}$. The temperature gradient at $10 \mathrm{~s}$ after immersion $\left(\Delta T_{10}\right)$ shows how quickly a quenchant reacts. The maximum temperature gradient $\left(\Delta T_{\max }\right)$ is of the greatest importance, showing the maximum thermal stresses developed during the quenching process. The time when $\Delta T_{\max }$ occurs is also important, because the temperature at $1 \mathrm{~mm}$ below the surface depends on it. If this temperature, at the moment of $\Delta T_{\max }$, is lower than the martensite start temperature $\left(M_{\mathrm{s}}\right)$ of the relevant steel, structural stresses due to martensite formation may be added to maximum thermal stresses, and distortion or cracking may occur. The temperature gradient $\Delta T_{100}$ at $100 \mathrm{~s}$ after immersion provides information on the duration of the quenching process.

\section{Results and Discussion}

The following discussion will be in two parts. The first part will be a quantitative review of an earlier study to investigate quenching performance of palm oil, canola oil, and a petroleum oil quenchant (Kalenol 32) under unagitated conditions at ambient temperature. ${ }^{21}$ These results will serve as the basis for Part 2 of this discussion, where the relative impact of different agitation rates and bath temperatures on quenching performance will be discussed.

\section{PART 1-DIFFERENCES BETWEEN UNAGITATED PETROLEUM OIL AND CANOLA OIL AND PALM OIL AT AMBIENT TEMPERATURE}

When performing tests with the Liscic/Petrofer probe and analyzing the results using the aforementioned specified criteria, substantial differences are found between the two vegetable oils canola oil and palm oil as shown in Table 4 .

For unagitated canola oil and palm oil quenching performance, the performance provided in Table 4 shows the following ${ }^{21}$ :

- The temperature gradient at $10 \mathrm{~s}$ after immersion $\left(\Delta T_{10}\right)$ is $174^{\circ} \mathrm{C}$ greater than for palm oil and the maximum temperature gradient $\left(\Delta T_{\max }\right)$ is $17.5 \%$ greater for palm oil and it occurs $17 \mathrm{~s}$ earlier.

- The time to the maximum HTC to occur is 2.5 times, indicating that palm oil reacts more quickly because it exhibits no film boiling phase, which is especially noteworthy since this suggests that palm oil may more applicable for quenching low-hardenability steels. Canola oil does exhibit some evidence of film boiling but it is not very pronounced. This more likely to be caused by the presence of a volatile contaminant than the presence of a low-boiling point triglyceride fraction of the canola oil. This requires more study for confirmation.

- The maximum value of the HTC $\left(\alpha_{\max }\right)$ is $17 \%$ greater for palm oil. The temperature gradient at $100 \mathrm{~s}$ after immersion $\left(\Delta T_{100}\right)$, although almost equal for both oils, occurs at a lower temperature for palm oil, indicating that the duration of the cooling process for palm oil will be shorter than for canola oil.

- When comparing canola oil and the petroleum oil with no agitation, the petroleum oil (Kalenol 32) exhibits a clearly distinguishable film boiling phase that changes to nucleate boiling phase (the second critical heat 
TABLE 4

Cooling parameters obtained from the cooling curve data obtained with canola oil, palm oil, and a commercial petroleum quench oil (Kalenol 32)

\begin{tabular}{|c|c|c|c|c|c|c|c|c|c|}
\hline Oil & Agitation & Bath Temp., ${ }^{\circ} \mathrm{C}$ & $\Delta T_{10},{ }^{\circ} \mathrm{C}$ & $\Delta T_{\max },{ }^{\circ} \mathrm{C}$ & $t_{\Delta T \max }, \mathrm{s}$ & $\Delta T_{100},{ }^{\circ} \mathrm{C}$ & $\alpha_{\max }, \mathrm{W} / \mathrm{m}^{2} \cdot \mathrm{K}$ & $T_{\alpha \max },{ }^{\circ} \mathrm{C}$ & $t_{\alpha \max }, \mathrm{s}$ \\
\hline \multirow[t]{3}{*}{ Canola Oil } & None & 23 & 261 & 335 & 31 & 78 & 2,560 & 606 & 26 \\
\hline & Moderate & 30 & 227 & 355 & 11 & 77 & 2,718 & 598 & 5.6 \\
\hline & Intensive & 30 & 372 & 388 & 14 & 83 & 2,725 & 600 & 5.1 \\
\hline \multirow[t]{3}{*}{ Canola Oil } & None & 60 & 160 & 340 & 18 & 52 & 2,650 & 604 & 11 \\
\hline & Moderate & 60 & 189 & 350 & 17 & 70 & 2,722 & 623 & 10 \\
\hline & Intensive & 60 & \multicolumn{7}{|c|}{ Not measured } \\
\hline \multirow[t]{3}{*}{ Palm Oil } & None & 23 & 173 & 390 & 16 & 66 & 2,985 & 591 & 11 \\
\hline & Moderate & 28 & 10 & 404 & 22 & 80 & 2,955 & 559 & 15 \\
\hline & High & 28 & 45 & 420 & 21 & 80 & 3,290 & 491 & 16 \\
\hline \multirow[t]{3}{*}{ Palm Oil } & None & 60 & 141 & 353 & 20 & 76 & 2,885 & 577 & 13 \\
\hline & Moderate & 60 & 0 & 527 & 21 & 136 & 3,075 & 510 & 13 \\
\hline & High & 60 & 0 & 377 & 22 & 86 & 3,611 & 565 & 14 \\
\hline \multirow[t]{3}{*}{ Kalenol 32} & None & 28 & 91 & 257 & 41 & 67 & 1,926 & 483 & 30 \\
\hline & Moderate & 28 & 64 & 285 & 38 & 107 & 2,117 & 512 & 21 \\
\hline & High & 28 & 146 & 320 & 24 & 100 & 2,303 & 528 & 20 \\
\hline \multirow[t]{3}{*}{ Kalenol 32} & None & 60 & 43 & 265 & 46 & 56 & 2,060 & 491 & 30 \\
\hline & Moderate & 60 & 52 & 288 & 38 & 92 & 2,675 & 561 & 29 \\
\hline & High & 60 & 96 & 318 & 28 & 96 & 2,448 & 492 & 21 \\
\hline
\end{tabular}

Note: The cooling curves from which these data were extracted are provided in the Appendix.

flux density $q_{\mathrm{cr}}^{2}$ ) at $620^{\circ} \mathrm{C}$, after $30 \mathrm{~s}$. As noted earlier, palm oil does not exhibit film boiling, and any film boiling that is apparent with canola oil is very weak.

- The results shown in Table 4 demonstrate a totally different heat extraction dynamic for the petroleum oil than for canola oil. The petroleum oil reacts faster initially but subsequently it exhibits slower cooling than that for canola oil. For canola oil, the time for the maximal HTC (tomax) to occur is substantially shorter, as evidenced by the higher temperature at which it occurs, and its maximal value is $32 \%$ greater than that for the petroleum oil quenchant. The maximal temperature gradient $\left(\Delta T_{\max }\right)$ is greater for canola oil, and the temperature gradient at $100 \mathrm{~s}\left(\Delta T_{100}\right)$ is equivalent to the petroleum oil, but it occurs at slightly lower temperatures.

- As previously noted, comparison of the cooling curves for palm oil and petroleum oil clearly show that palm oil does not exhibit film boiling. Furthermore, the data in Table 4 show that the HTC $\left(t_{\alpha} \max \right)$ is $28 \mathrm{~s}$ shorter for palm oil, and the maximal temperature gradient $\left(\Delta T_{\max }\right)$ is $32 \%$ greater and occurs $22 \mathrm{~s}$ earlier. The value of the maximal HTC $(\alpha \max )$ is $41 \%$ greater for palm oil, and it occurs at a higher temperature. The temperature gradient at $100 \mathrm{~s}\left(\Delta T_{100}\right)$ is slightly greater than for the petroleum oil and it occurs at much lower temperatures.

\section{GENERAL COMMENTS REGARDING APPARENT FILM BOILING OF VEGETABLE OILS}

It is very important to put the results shown for palm oil and canola oil in context, because vegetable oils (if present as a "pure" triglyceride oil) do not boil. The highest cooking (use) temperature for a vegetable oil is limited by the temperature at which the oil begins to smoke. Typical smoke points for common vegetable oils may vary from $121^{\circ} \mathrm{C}$ to $>232^{\circ} \mathrm{C}\left(250^{\circ} \mathrm{F}\right.$ to $\left.>450^{\circ} \mathrm{F}\right)$. The exact smoke points cannot be cited because of the normal compositional variation, refining method, seed variety, and even the climate and weather during the plant's growing season. However, typical smoke points for common vegetable oils are as follows: for safflower oil, $163^{\circ} \mathrm{C}-177^{\circ} \mathrm{C}$ $\left(325^{\circ} \mathrm{F}-350^{\circ} \mathrm{F}\right)$; corn oil, $204^{\circ} \mathrm{C}-213^{\circ} \mathrm{C}\left(400^{\circ} \mathrm{F}-415^{\circ} \mathrm{F}\right)$; peanut oil, $216^{\circ} \mathrm{C}-221^{\circ} \mathrm{C}\left(420^{\circ} \mathrm{F}-430^{\circ} \mathrm{F}\right)$; cottonseed oil, $218^{\circ} \mathrm{C}-227^{\circ} \mathrm{C}\left(425^{\circ} \mathrm{F}-440^{\circ} \mathrm{F}\right)$; canola oil, $224^{\circ} \mathrm{C}-229^{\circ} \mathrm{C}\left(435^{\circ} \mathrm{F}-445^{\circ} \mathrm{F}\right)$; and sunflower and soybean oils, $227^{\circ} \mathrm{C}-232^{\circ} \mathrm{C}\left(440^{\circ} \mathrm{F}-450^{\circ} \mathrm{F}\right){ }^{22}$ At atmospheric pressure and temperatures greater than the smoke point, vegetable oils degrade; they do not boil. 
However, commercially available vegetable oils are not pure single component fluids, but they contain a range of different triglyceride structures that are dependent on the particular seed oil. Normally they are refined by a variety of possible methods, but even after refining, they may still potentially contain small quantities of by-products. In addition to monoglyceride and diglyceride structures, vegetable oils may also contain free fatty acids, tocopherols, sterols, phenolic compounds, phospholipids, and other variants, as well as low concentrations of water. ${ }^{23,24}$ Some of these compounds contribute to potential volatility, which may be observed as film boiling during immersion quenching of hot steel. Unless the as-purchased vegetable oils are further purified, they all contain a number of these potential by-products at varying concentrations, depending on the refining process and its effectiveness. Both of the vegetable oils reported here were used in the as-purchased condition after the addition of the propyl gallate antioxidant. However, based on the cooling curves obtained, it is concluded that the canola oil used for this work contains sufficient non-triglyceride impurities to exhibit the apparent film boiling behavior observed which was not observed for the palm oil, which exhibited minimal, if any, film boiling behavior in this work. Typical refining and purification practice and composition of commercial palm oil is described in Gee. ${ }^{25}$

\section{PART 2-ANALYSIS OF AGITATION AND BATH TEMPERATURE EFFECTS}

The cooling parameters for canola oil, palm oil, and the commercial petroleum oil quenchant evaluated at different agitation and bath temperature are summarized in Table 4. These data were obtained from the experimental curves shown in the Appendix.

When compared to unagitated canola oil, the $\Delta T_{10}$ value decreases and then increases as the agitation rate increases from none to moderate to intensive. The decrease in $\Delta T_{10}$ value is intuitive since the surface heat transfer would be expected to increase because of the more rapid rate of interfacial heat removal as the hot fluid is carried away from the surface by the quenching fluid. The increase in the $\Delta T_{10}$ value for intensive quenching was even greater than for still quenching. This increase in $\Delta T_{10}$ value may be due to microbubble formation that is due to air entrainment at these very high agitation rates. Unfortunately, this was not confirmed at the time the work was done.

The $\alpha_{\max }$ value increased with the increasing agitation rate, although the greatest increase was observed for moderate agitation versus no agitation. A further, although marginal, increase was observed as the agitation rate was increased from moderate to intensive. The $t_{\Delta T \max }$ time substantially decreased (31-11 s) when the agitation rate was increased from none to moderate with a marginal increase (11-14 s) as the agitation rate was increased from moderate to intensive. The maximum temperature gradient $\left(\Delta T_{\max }\right)$ increased as the agitation rate was increased: $335,355,388$. However, as observed with the other parameters, the actual temperature at which $\alpha_{\max }$ occurs $\left(T_{\alpha \max }\right)$ decreased only slightly as agitation increased relative to no agitation. Although there is unexpected experimental variability when comparing moderate and intensive agitation rates, it may still be concluded that the application of moderate agitation rates will significantly increase heat transfer, and a further increase in the agitation rate from moderate to intensive may produce a slightly deleterious effect on heat transfer increases.

Increasing bath temperature from ambient to $60^{\circ} \mathrm{C}$ generally resulted in relatively little difference, whether it be an increase or decrease, in these parameters. This increase in temperature $\left(\Delta T_{\text {fluid }}\right)$ would result in a substantial decrease in fluid viscosity, resulting in faster cooling rates, as suggested by the fluid viscosities of 35.14 and $8.7 \mathrm{cSt}$ $\left(\mathrm{mm}^{2} / \mathrm{s}\right)$ at $40^{\circ} \mathrm{C}$ and $100^{\circ} \mathrm{C}$, respectively, as shown in Table 1 . Therefore, since decreasing fluid viscosity produces comparatively less sensitivity to agitation rate effects, cooling parameters for $60^{\circ} \mathrm{C}$ relative to ambient temperature shown in Table 4 were greater for increasing bath temperature than for increasing agitation rate.

For palm oil, increasing the agitation rate from none to moderate resulted in the $\Delta T_{10}$ value, which is the temperature gradient between the center and point $1 \mathrm{~mm}$ below surface at $10 \mathrm{~s}$ after immersion, to exhibit a large decrease from $\left(173^{\circ} \mathrm{C}\right.$ to $\left.10^{\circ} \mathrm{C}\right)$, which then increased from $\left(10^{\circ} \mathrm{C}-45^{\circ} \mathrm{C}\right)$ as the agitation rate is increased from moderate to intensive. The initial decrease is due to an agitation-induced mechanical rupture of an unstable vapor film which was observed with no agitation. (Contrast this observation with canola oil, which did not produce a similar film boiling effect as discussed in the previous section.) However, as observed with canola oil, further increasing the agitation rate from moderate to intensive resulted in a subsequent increase of the $\Delta T_{10}$ value. 
As previously suggested, this may be due to agitation-induced air entrainment of the intensively agitated fluid, which would be expected to produce correspondingly lower cooling rates.

No significant increase in the $\alpha_{\max }$ value was observed for palm oil as the agitation rate was increased from none to moderate $(2,985$ versus 2,955$)$. However, increasing the agitation rate from moderate to intensive did produce a significant increase in the $\alpha_{\max }$ value $(2,955$ to 3,290$)$. While the overall increase in the $\alpha_{\max }$ value was expected, a greater impact of moderate agitation was expected as well. Thus, increasing agitation did, in fact, result in increasing $\alpha_{\max }$; a more progressive increase would have been expected throughout the overall agitation rate increasing process, as observed for canola oil.

The $t_{\Delta T \text { max }}$, the time from immersion to the moment when $\alpha_{\max }$ occurs, increased from (16-22 s) as the agitation rate was increased from none to moderate and remained essentially unchanged with a further agitation increase from moderate to intensive (22 to $21 \mathrm{~s}$ ). However, it is cautioned that when observing these data for palm oil relative to canola oil and petroleum quench oil, while differences are observed, they may not be particularly significant, suggesting that the cooling time may not be largely affected by agitation rate.

The maximum temperature gradient $\left(\Delta T_{\max }\right)$ of palm oil decreased as the agitation rate was increased: 390 , 404,420 . The temperature at which $\alpha_{\max }$ occurs $\left(T_{\alpha \max }\right)$ decreased with increasing agitation rate $\left(591^{\circ} \mathrm{C}, 559^{\circ} \mathrm{C}\right.$, $491^{\circ} \mathrm{C}$ ), which is the expected effect on cooling of increasing interfacial fluid flow.

Increasing the bath temperature of palm oil from ambient to $60^{\circ} \mathrm{C}$ generally resulted in a dramatic decrease in in the $\Delta T_{10}$ value, with the greatest effect observed when the agitation rate is increased from none to moderate $\left(141^{\circ} \mathrm{C}\right.$ to $\left.0^{\circ} \mathrm{C}\right)$. This effect was even greater than observed for canola oil with increasing bath temperature. However, as for canola oil, the effect may be explained by an even greater decrease in viscosity with increasing temperature, as shown in Table 1, by the fluid viscosities of 40.39 and $8.53 \mathrm{cSt}\left(\mathrm{mm}^{2} / \mathrm{s}\right)$ at $40^{\circ} \mathrm{C}$ and $100^{\circ} \mathrm{C}$, respectively. However, for palm oil, a greater increase in the $\alpha_{\max }$ value with increasing agitation rate at a bath temperature of $60^{\circ} \mathrm{C}$ was observed $(2,885,3,075,3,611)$ than obtained for canola oil (see Table 4).

The effect of bath temperature and agitation of Kalenol 32, a commercial petroleum oil quenchant, was also evaluated for comparison to the quenching results obtained for canola oil and palm oil. The results obtained are also summarized in Table 4.

The effect of increasing agitation at ambient bath temperature $\left(28^{\circ} \mathrm{C}\right.$, in this case) was similar to that observed for canola oil, where the $\Delta T_{10}$ value decreased as the agitation increased from none to moderate $\left(91^{\circ} \mathrm{C}\right.$ to $64^{\circ} \mathrm{C}$ ) and then increased as the agitation was increased from moderate to intensive $\left(64^{\circ} \mathrm{C}\right.$ to $\left.140^{\circ} \mathrm{C}\right)$. This effect was attributed to a substantial increase in air entrainment at the highest agitation rate as discussed earlier for canola oil. Without this possible air entrainment effect, the increase in agitation from moderate to intensive would have been expected to result in a further decrease in the $\Delta T_{10}$ value. As with canola oil, for this quenching system, it is apparent that the optimal impact of agitation is obtained for moderate flow rates.

As would be expected, increasing agitation should result in increased HTCs $\left(\alpha_{\max }\right)$, which were observed with the values increasing from 1,926 to 2,117 to 2,303, respectively, as the agitation was increased from none to moderate to intensive. This is consistent with the behavior of both palm oil and canola oil. However, the $\alpha_{\max }$ values are considerably lower than either canola oil or palm oil. This cannot be attributed to fluid viscosity, since the Kalenol 32 values are lower than either canola oil or palm oil ( 32 and $5.4 \mathrm{cSt}$ at $40^{\circ} \mathrm{C}$ and $100^{\circ} \mathrm{C}$, respectively). It is expected that these results are, in fact, related to poorer thermophysical properties of the petroleum base stock compared to either vegetable oil. Unfortunately, these values have not been reported for all of the fluids.

The $t_{\Delta T \max }$ time decreased with increasing agitation $(41,38,24 \mathrm{~s})$. The maximum temperature gradient $\left(\Delta T_{\max }\right)$ increased for Kalenol 32 with increasing agitation rate $\left(257^{\circ} \mathrm{C}, 285^{\circ} \mathrm{C}, 320^{\circ} \mathrm{C}\right)$. The temperature at which $\alpha_{\max }$ occurs $\left(T_{\alpha \max }\right)$ increased with increasing agitation rate $(483,512,528)$. These are effects that would be expected with increasing interfacial flow rates and indicate that slower heat transfer is obtained with the petroleum-based Kalenol 32 versus a vegetable oil such as canola oil or palm oil.

At a higher bath temperature, $60^{\circ} \mathrm{C}$ versus $28^{\circ} \mathrm{C}$, the $\alpha_{\max }$ value does show a small increase with increasing agitation from none to moderate (2,060 to 2,675); however, further increase in agitation from moderate to intensive resulted in only a minimal change, a decrease from 2,675 to 2,448 . Overall, while the $\alpha_{\max }$ value increased slightly 
with the increasing bath temperature, the effect was not large. The other cooling parameters shown in Table 4 for increasing the agitation of Kalenol 32 at a $60^{\circ} \mathrm{C}$ bath temperature behaved consistently, as one would expect.

\section{Conclusions}

This study was conducted as a continuation of previous work conducted to assess the quenching properties of canola oil, palm oil, and a commercial petroleum oil quenchant under unagitated conditions. This study was conducted with the same quenchants to compare the effect of agitation at 0 (none), 500 (moderate), and 800 (intensive) $\mathrm{r} / \mathrm{min}$ (referring to the rotational speed of the marine propeller shaft), which correspond to $0,0.5$, and $0.8 \mathrm{~m} / \mathrm{s}$. In most cases, two bath temperatures ambient $\left(23^{\circ} \mathrm{C}\right.$ or $\left.28^{\circ} \mathrm{C}\right)$ and $60^{\circ} \mathrm{C}$ were used.

Previously it was shown that the quenching intensity of liquid quenchants could be effectively characterized under industrial conditions using the large section size Liscic/Petrofer probe. This evaluation was based on dynamic heat extraction from the quenched workpiece, which is best represented by the changing temperature gradients. Each test provides three experimentally recorded cooling curves and diagrams of calculated surface temperature and HTC as a function of time and also as function of surface temperature. In order to impartially and exactly analyze each test, characteristic criteria from these diagrams are applied. These analyses were applied for this study as well.

First of all, it is important to realize that vegetable oils do not boil. Instead, they undergo thermal-oxidative degradation as temperatures approach and exceed their flash point. Therefore, film boiling would not be expected, as was the case in this study with canola oil. However, if the vegetable oil is poorly refined or has undergone degradation during processing, storage, or both, the resulting oxidative by-products produced will cause the oil to exhibit a noticeable film boiling effect as was observed with palm oil, although not as pronounced as observed with the petroleum oil quenchant.

The imposition of some agitation did reduce the stability of the vapor film, if present. However, the resulting thermal gradient did typically decrease with moderate agitation but increased again substantially as the agitation was further increased from moderate to intensive, especially for the vegetable oils compared to petroleum oil. Although it has yet to be confirmed, this effect could be explained by increased air entrainment when excessive agitation is applied. Nevertheless, it is concluded that there is an optimal, system-dependent agitation. Higher degrees of agitation in commercial systems may not always be best.

Based on the results reported here, heat transfer increased with the agitation rate increasing from none to moderate. However, this was not always true as the agitation rate was increased from moderate to intensive. This may also be explained by an air entrainment effect where above a critical value and with air bubble saturation of the fluid, the actual quenching medium may, in fact, be a "bubbly fluid." This was true for the three fluids evaluated. This is important for commercial quenching systems and must be more carefully and quantitatively assessed experimentally.

Increasing the bath temperature did have some effect but not as expected. Generally, it would be expected that while increasing the agitation rate it would be expected to increase heat transfer because increased interfacial fluid flow would more efficiently provide supplies of cooler fluid. Conversely, increasing bath temperature would be expected to produce slower cooling because of reduced interfacial $\Delta T$ between the cooling surface and bulk fluid. However, this may not necessarily be true if the fluid viscosity is decreased sufficiently and if the fluid is relatively more conductive than a petroleum oil. This is suggested by the results obtained in this study where, in some cases, the highest heat transfer was obtained with the $60^{\circ} \mathrm{C}$ bath temperature relative to ambient.

In conclusion, the results reported here do show that agitation and bath temperature are important. Furthermore, the results do suggest that there is an optimal agitation rate and that it is not always true that higher agitation rates produce increasing higher heat transfer under all conditions. These results show an interrelationship between bath temperature and agitation rate that was not possible to delineate with the experimental design used here. These effects should be studied further to not only examine the interdependence of these variables but with the temperature-dependent thermal properties of these fluids. 


\section{Appendix: Cooling Curve Performance Curves}

\section{APPENDIX A: CANOLA OIL}

FIG. A.1 Cooling time-temperature curves of canola oil at $23^{\circ} \mathrm{C}$ without agitation.

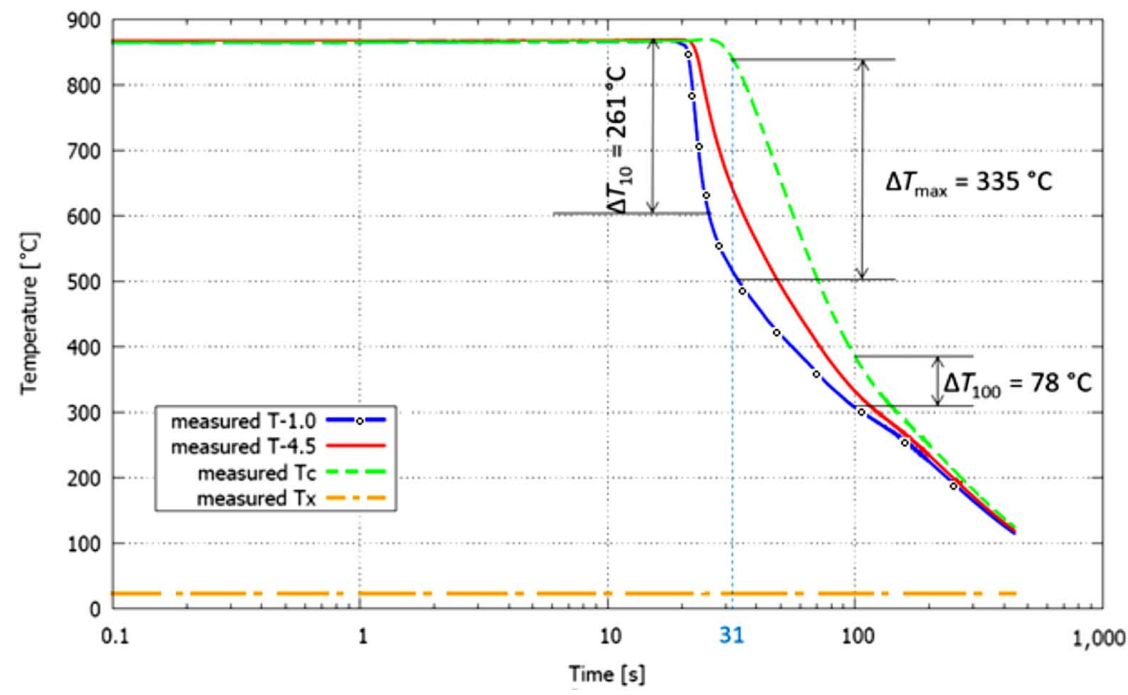

FIG. A.2 Cooling time-temperature curves of canola oil at $23^{\circ} \mathrm{C}$ moderate agitation.

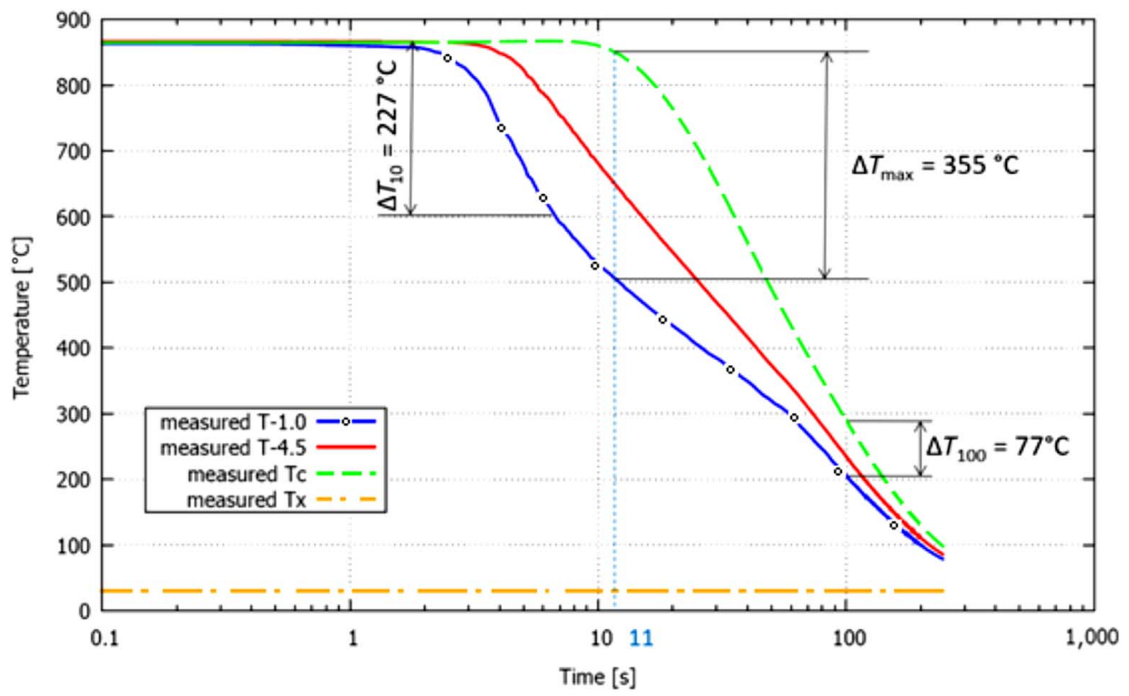


FIG. A.3 Cooling time-temperature curves of canola oil at $30^{\circ} \mathrm{C}$ intensive agitation.

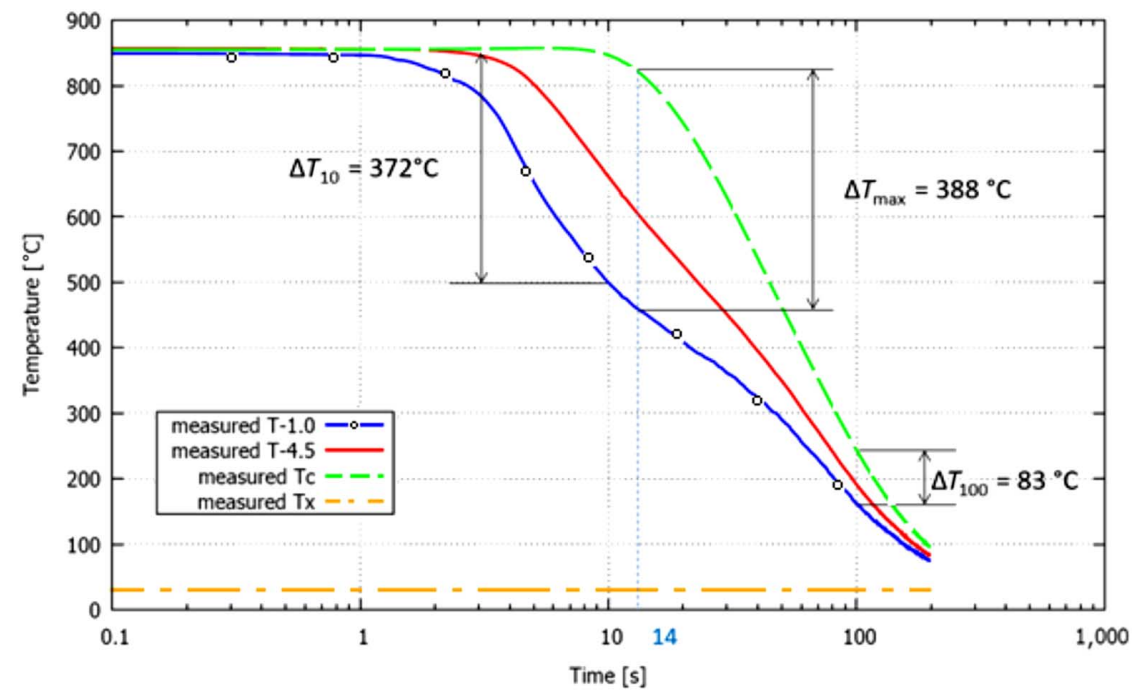

FIG. A.4 Cooling time-temperature curves of canola oil at $60^{\circ} \mathrm{C}$ without agitation.

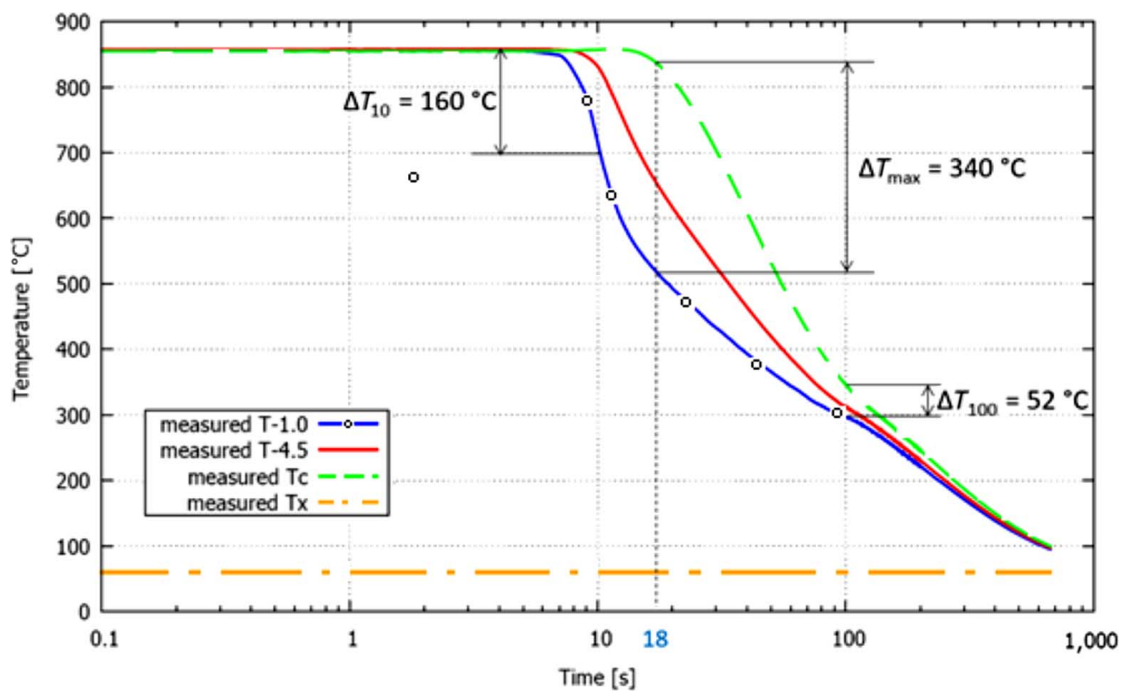


FIG. A.5 Cooling time-temperature curves of canola oil at $60^{\circ} \mathrm{C}$ moderate agitation.

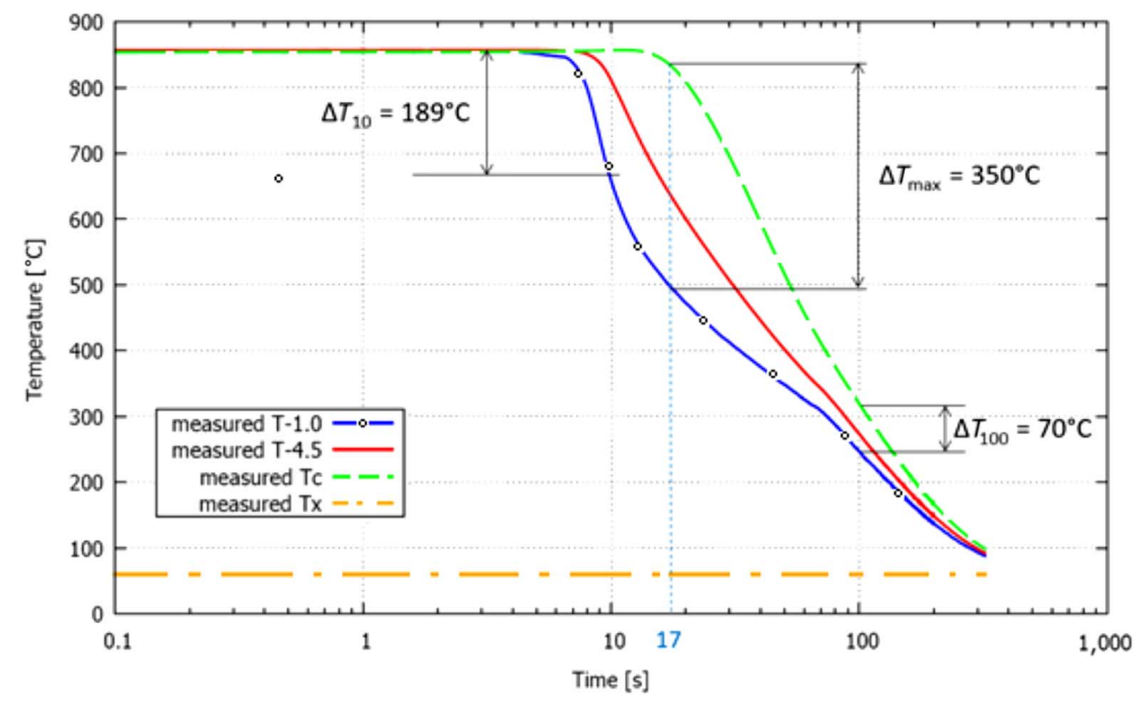

FIG. A.6 Cooling time-temperature curves of canola oil $+0.5 \%$ propyl gallate at $30^{\circ} \mathrm{C}$ without agitation.

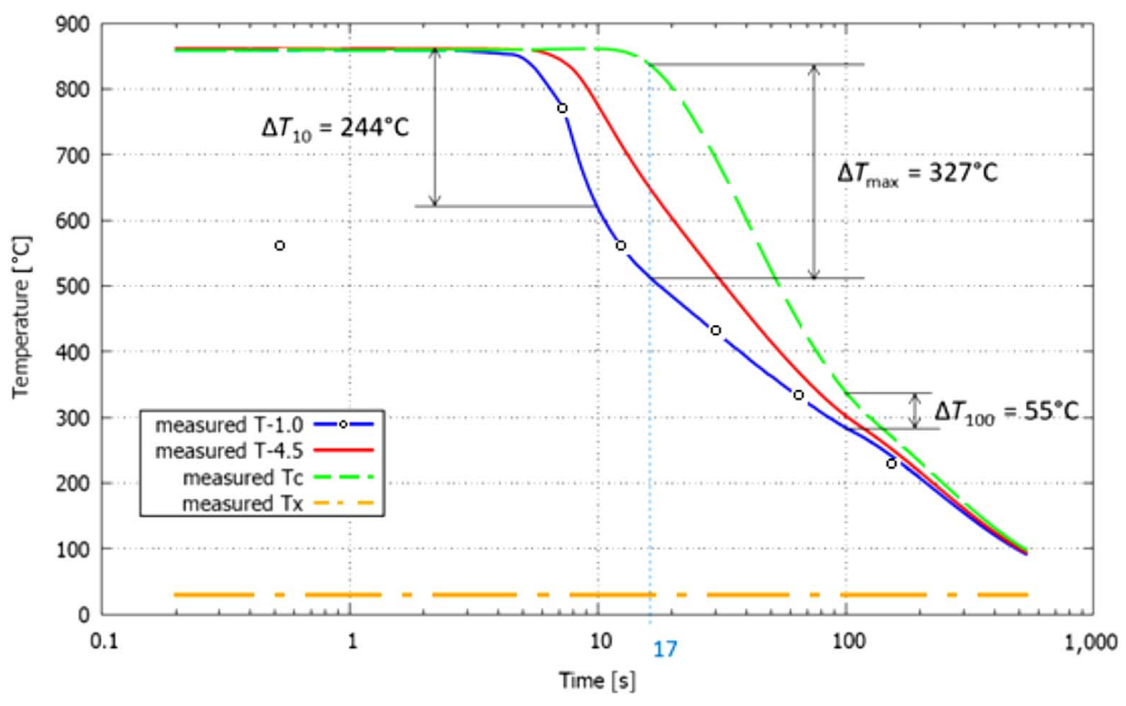


FIG. A.7 Cooling time-temperature curves of canola oil $+0.5 \%$ propyl gallate at $26^{\circ} \mathrm{C}$ moderate agitation.

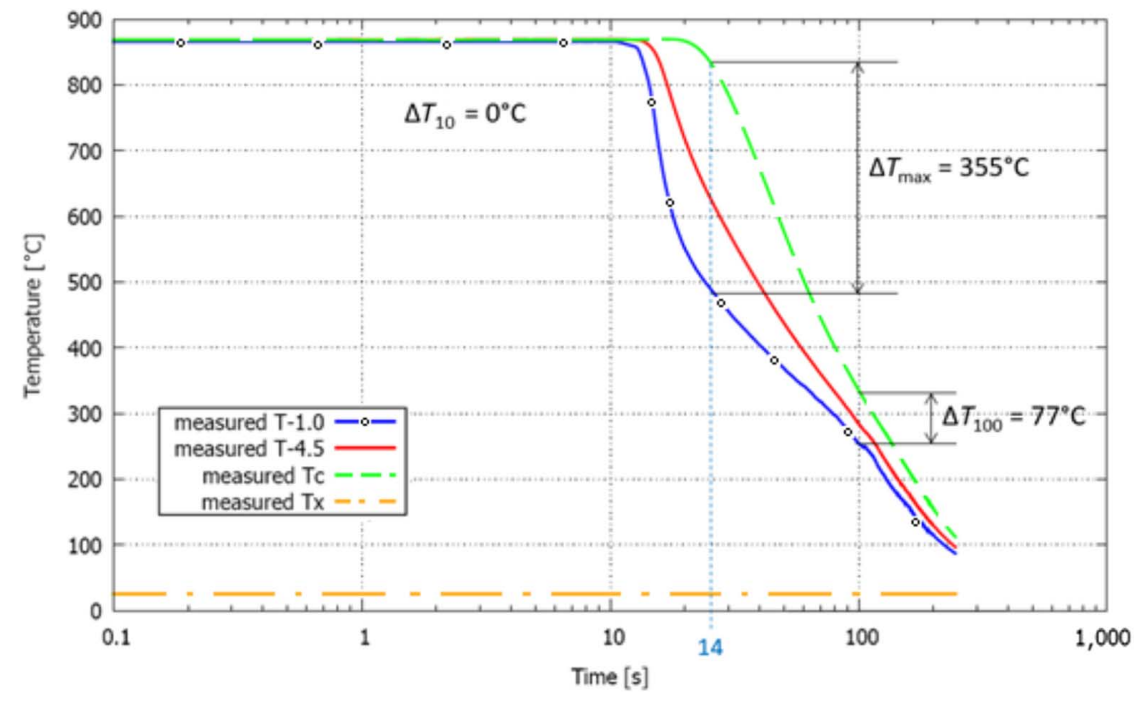

FIG. A.8 Cooling time-temperature curves of canola oil $+0.5 \%$ propyl gallate at $26^{\circ} \mathrm{C}$ intensive agitation.

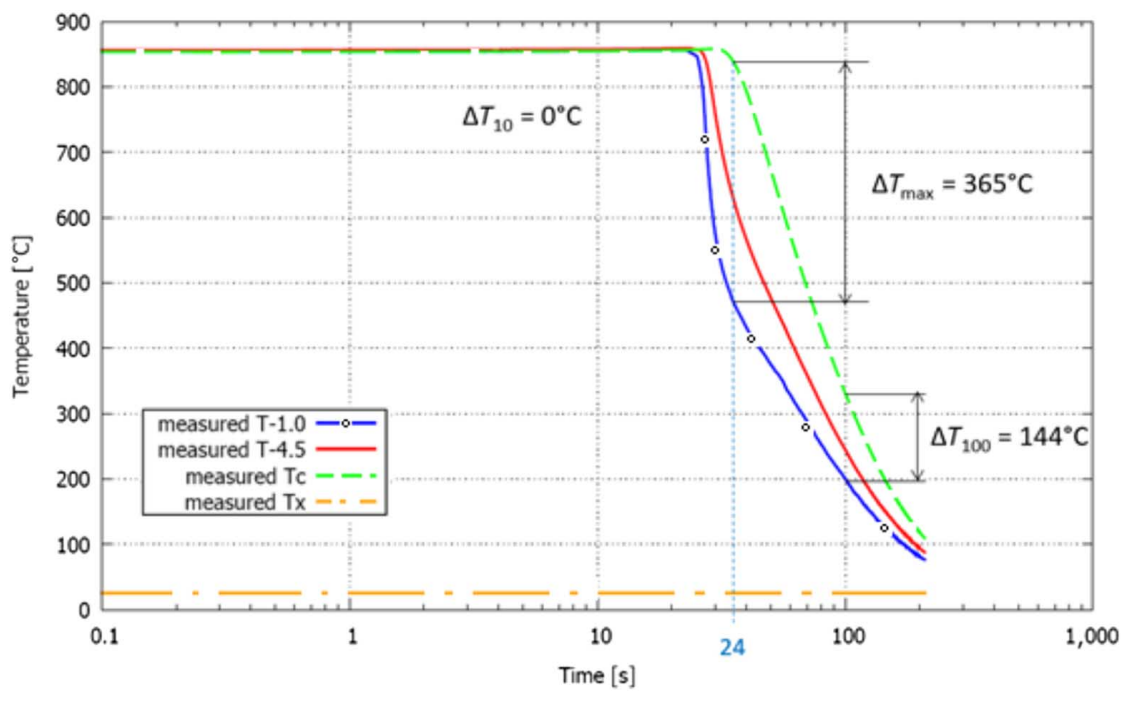


FIG. A.9 Cooling time-temperature curves of canola oil $+0.5 \%$ propyl gallate at $60^{\circ} \mathrm{C}$ without agitation.

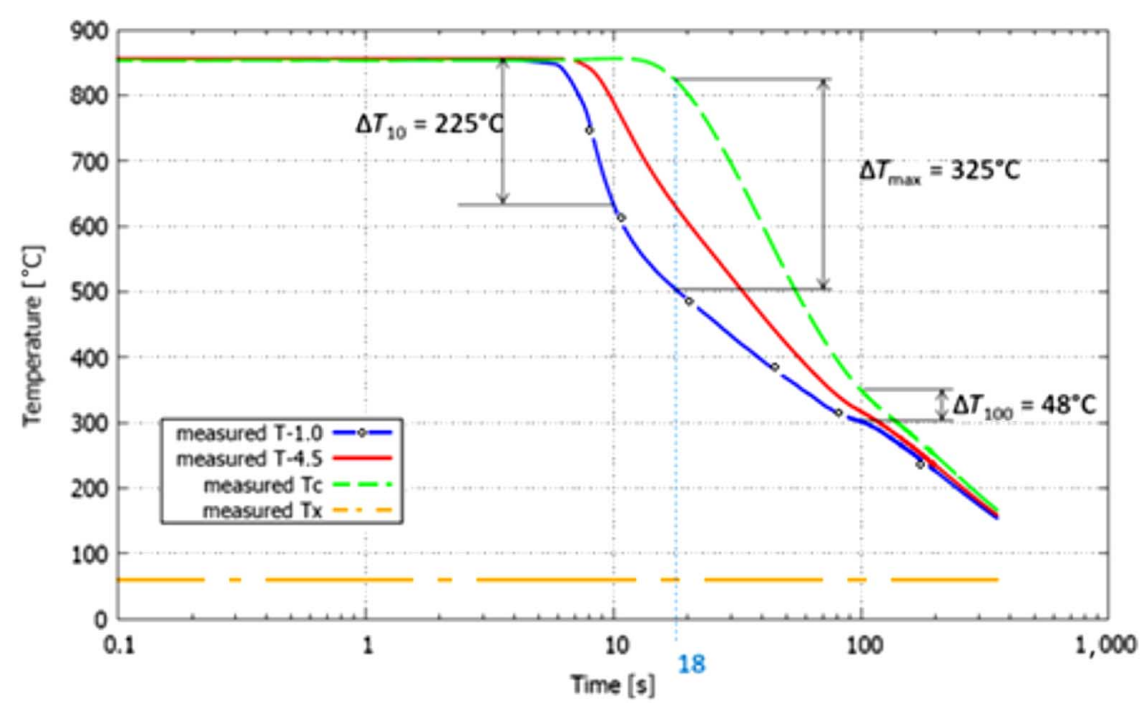

FIG. A.10 Cooling time-temperature curves of canola oil $+0.5 \%$ propyl gallate at $60^{\circ} \mathrm{C}$ moderate agitation.

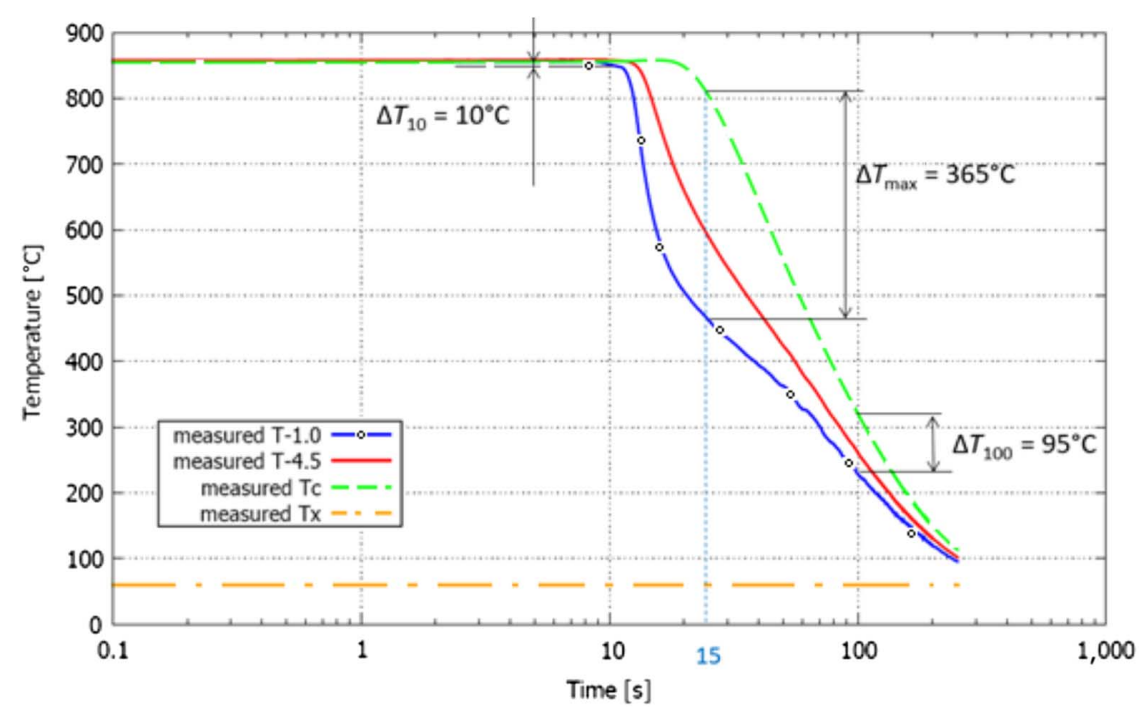


FIG. A.11 Cooling time-temperature curves of canola oil $+0.5 \%$ propyl gallate at $60^{\circ} \mathrm{C}$ intensive agitation.

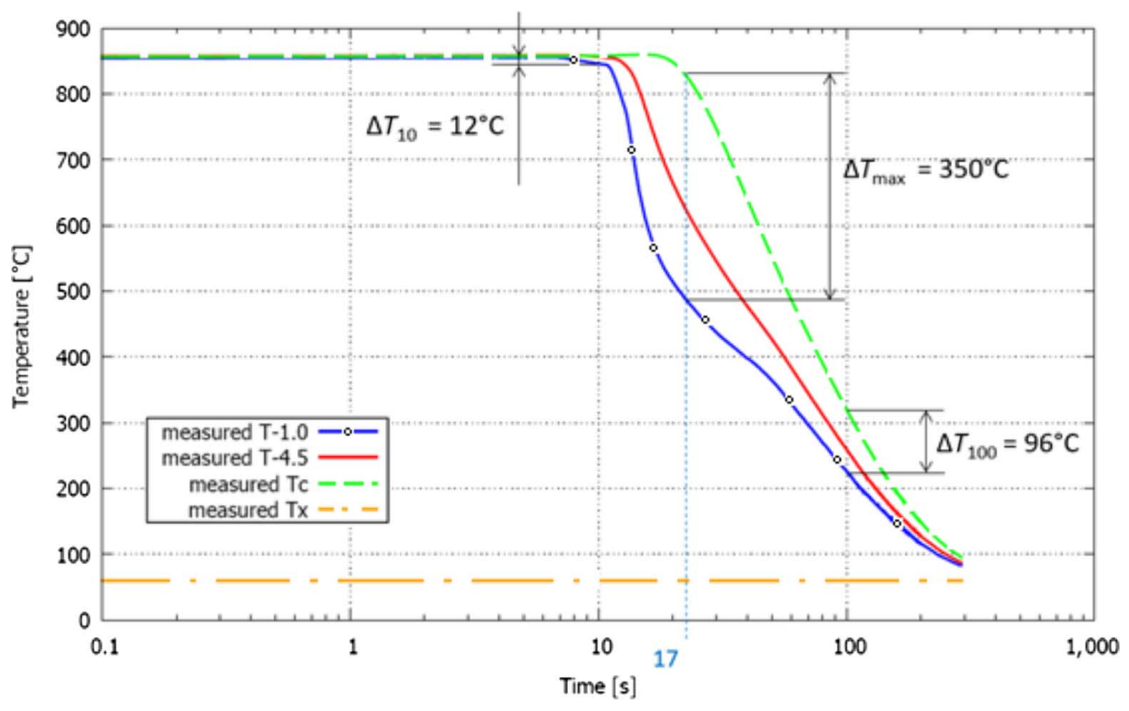

APPENDIX B: PALM OIL

FIG. A.12 Cooling time-temperature curves of palm oil at $23^{\circ} \mathrm{C}$ without agitation.

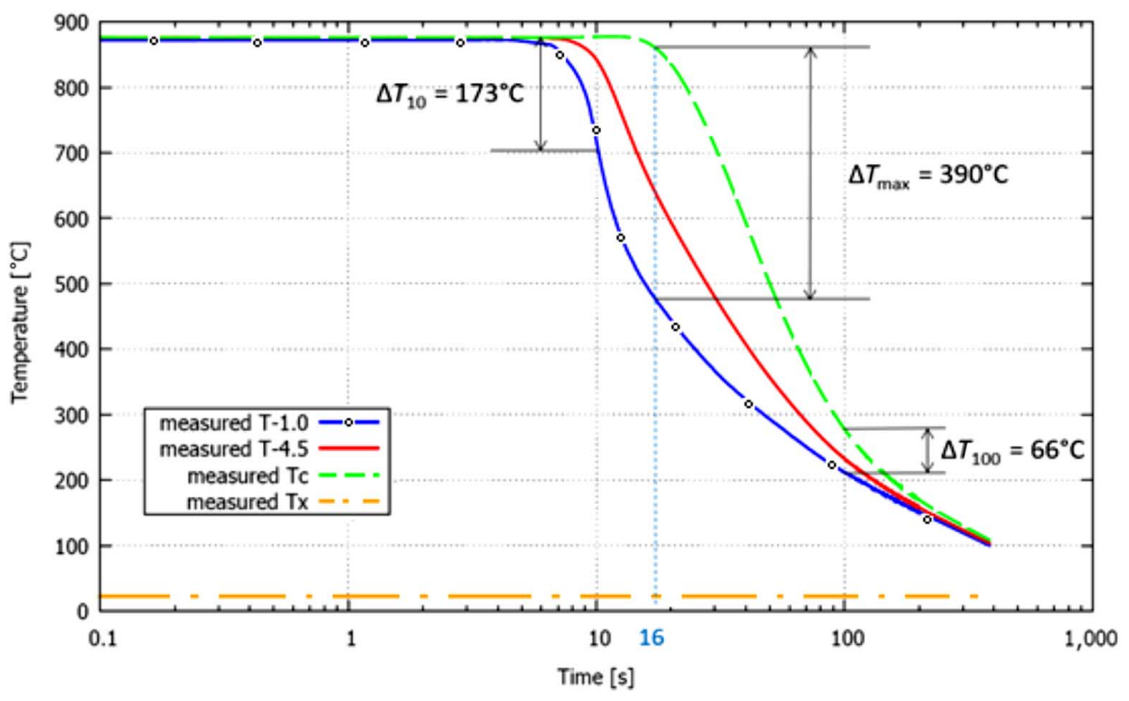


FIG. A.13 Cooling time-temperature curves of palm oil at $28^{\circ} \mathrm{C}$ moderate agitation.

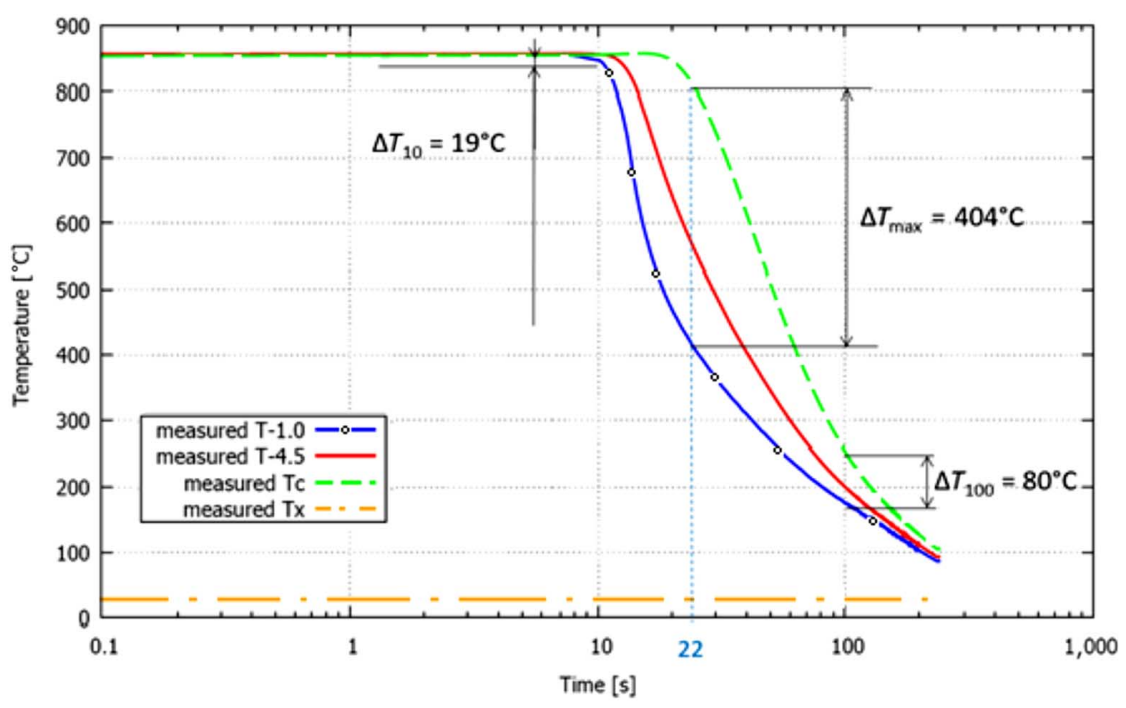

FIG. A.14 Cooling time-temperature curves of palm oil at $28^{\circ} \mathrm{C}$ intensive agitation.

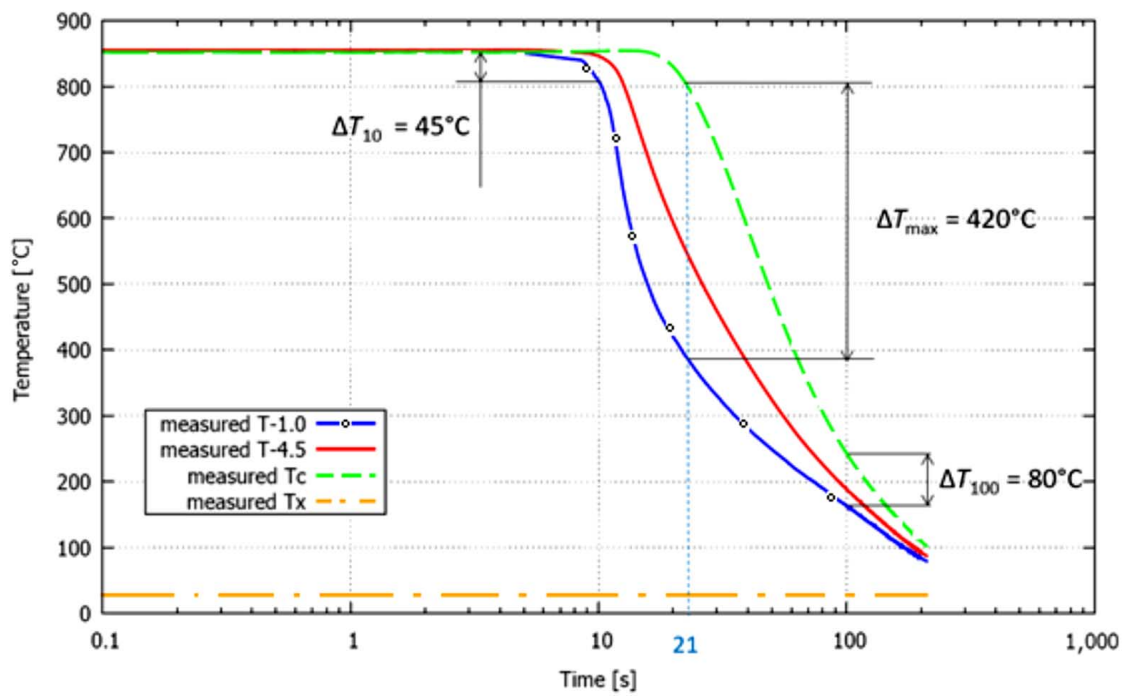


FIG. A.15 Cooling time-temperature curves of palm oil at $60^{\circ} \mathrm{C}$ without agitation.

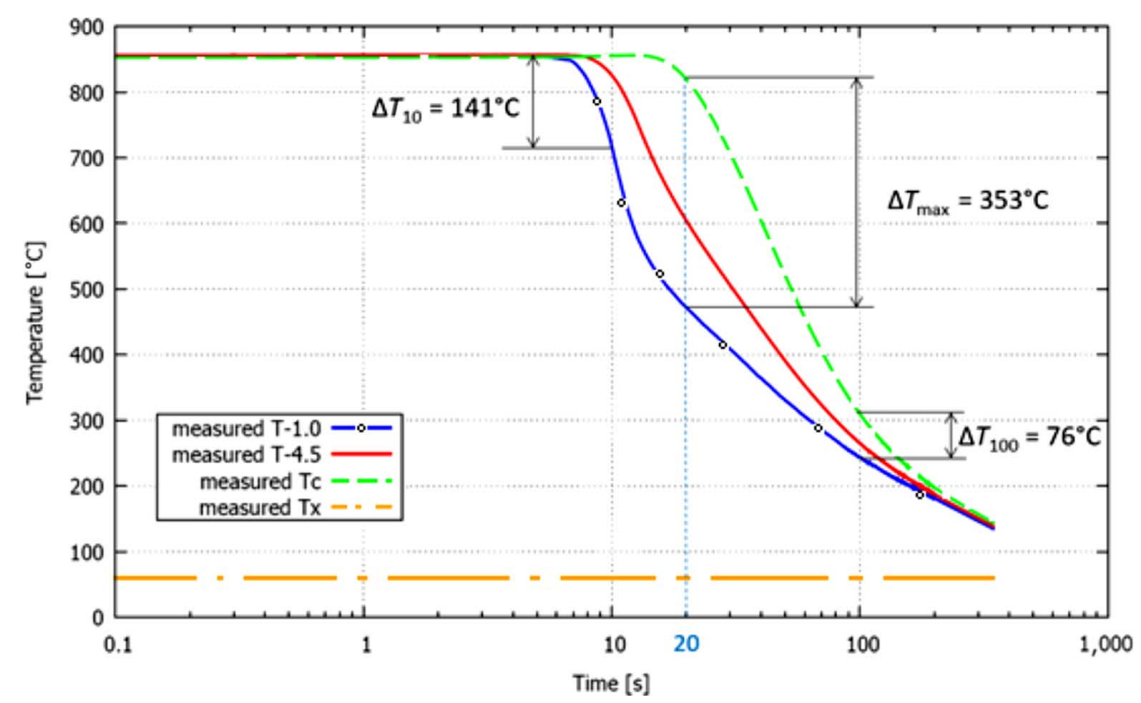

FIG. A.16 Cooling time-temperature curves of palm oil at $60^{\circ} \mathrm{C}$ moderate agitation.

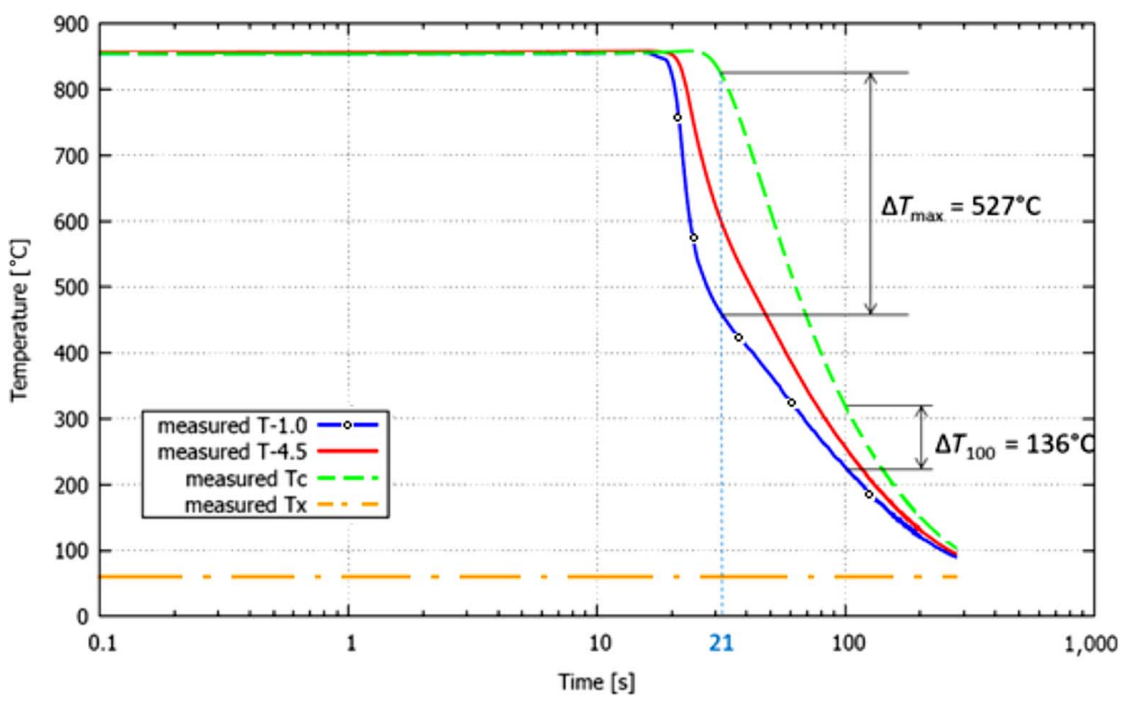


FIG. A.17 Cooling time-temperature curves of palm oil at $60^{\circ} \mathrm{C}$ intensive agitation.

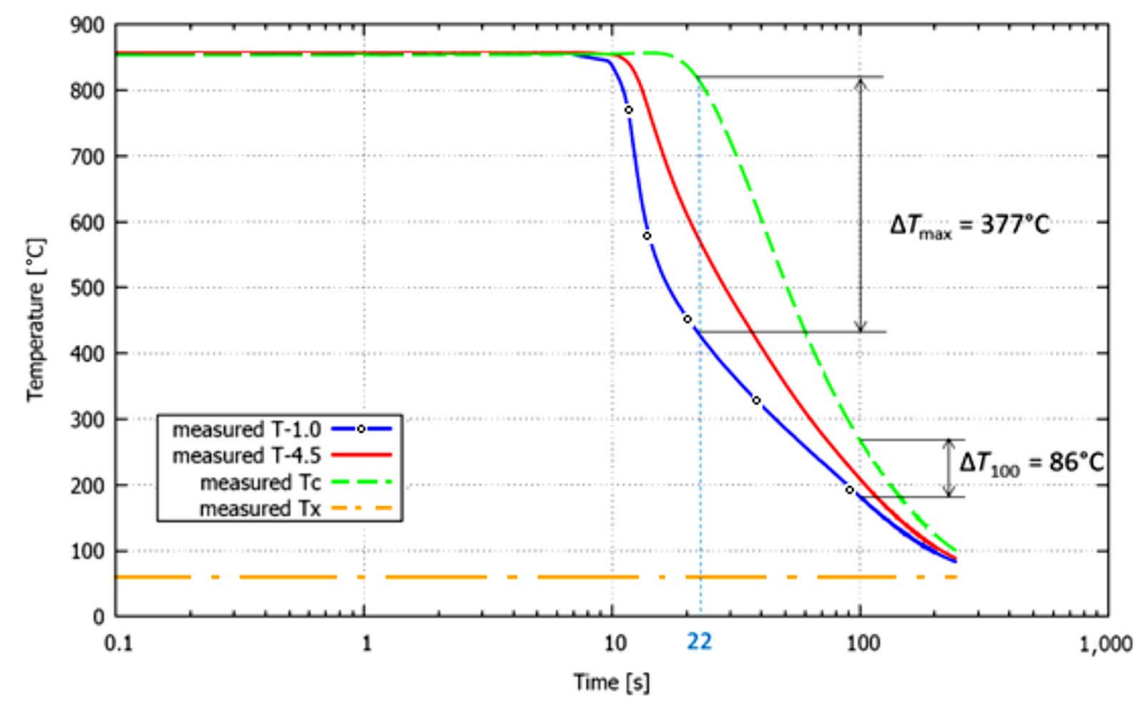

FIG. A.18 Cooling time-temperature curves of palm oil $+0.5 \%$ propyl gallate at $23^{\circ} \mathrm{C}$ without agitation.

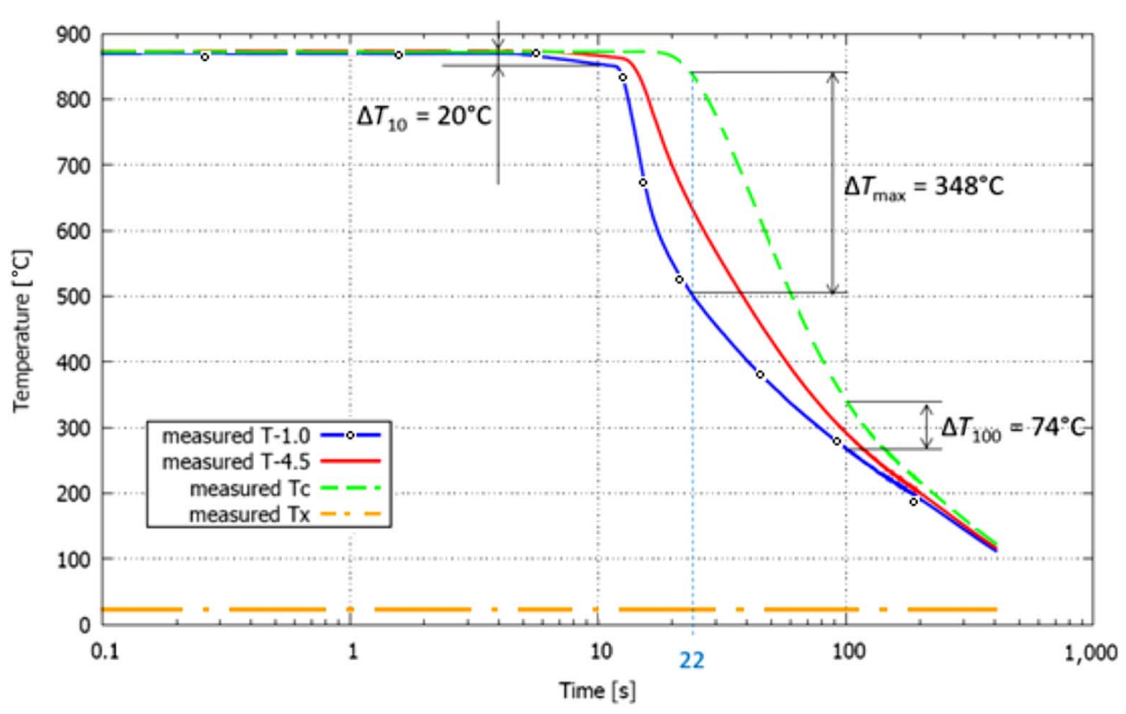


FIG. A.19 Cooling time-temperature curves of mineral oil (Kalenol 32) at $28^{\circ} \mathrm{C}$ without agitation.

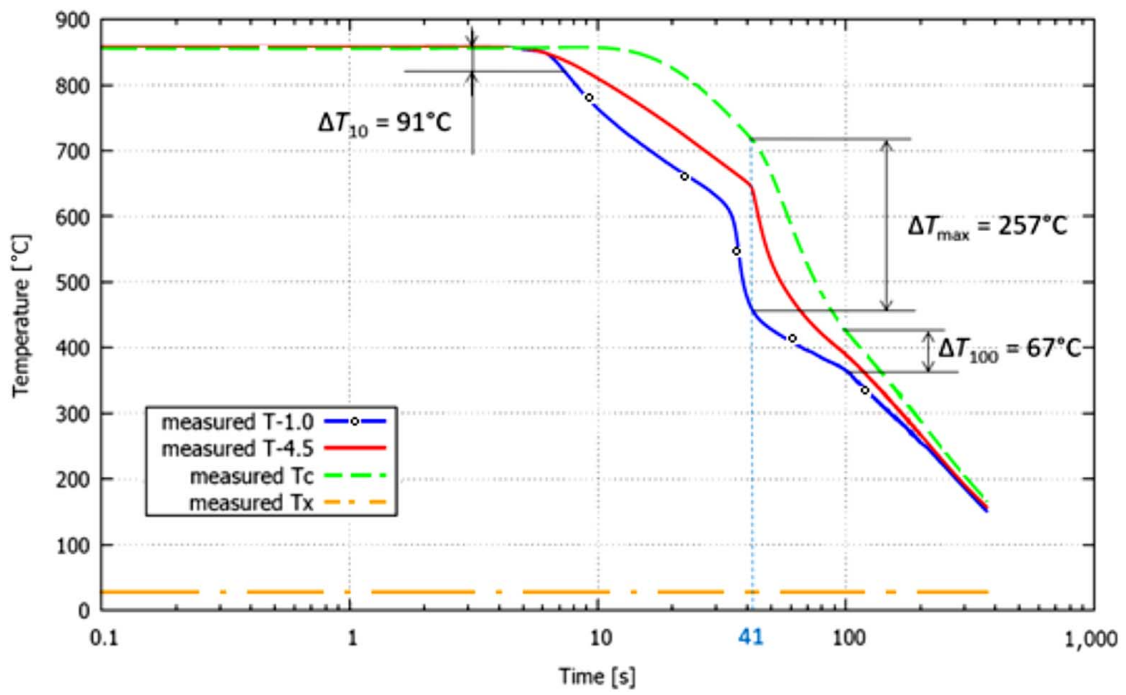

FIG. A.20 Cooling time-temperature curves of mineral oil (Kalenol 32) at $28^{\circ} \mathrm{C}$ moderate agitation.

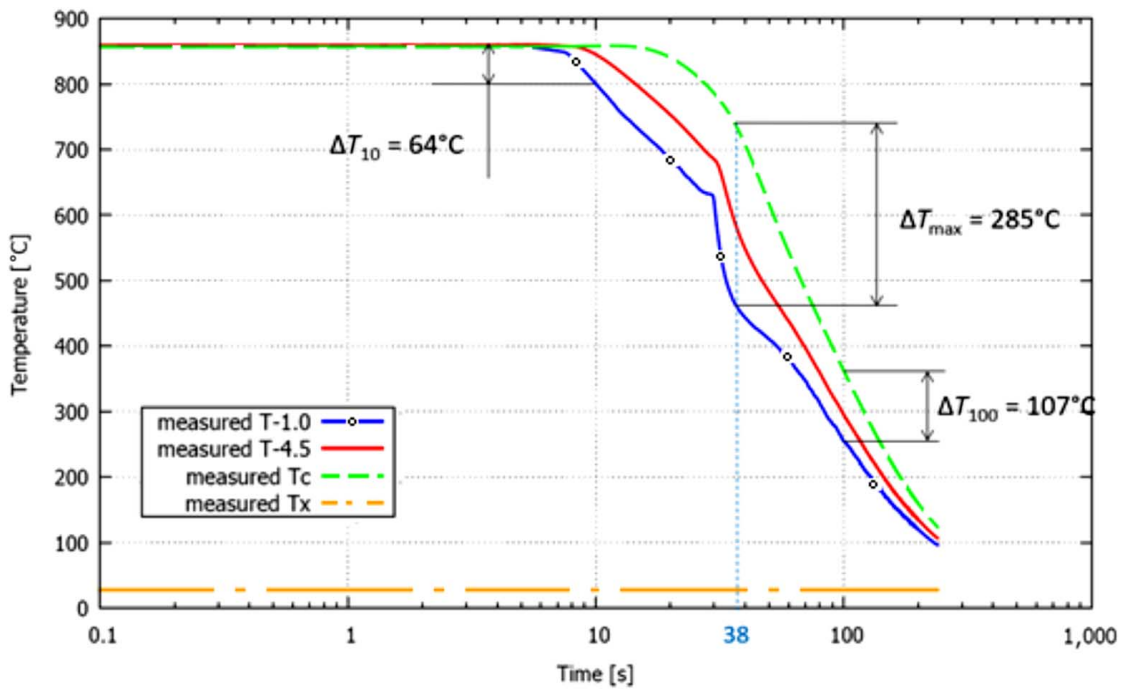


FIG. A.21 Cooling time-temperature curves of mineral oil (Kalenol 32) at $28^{\circ} \mathrm{C}$ intensive agitation.

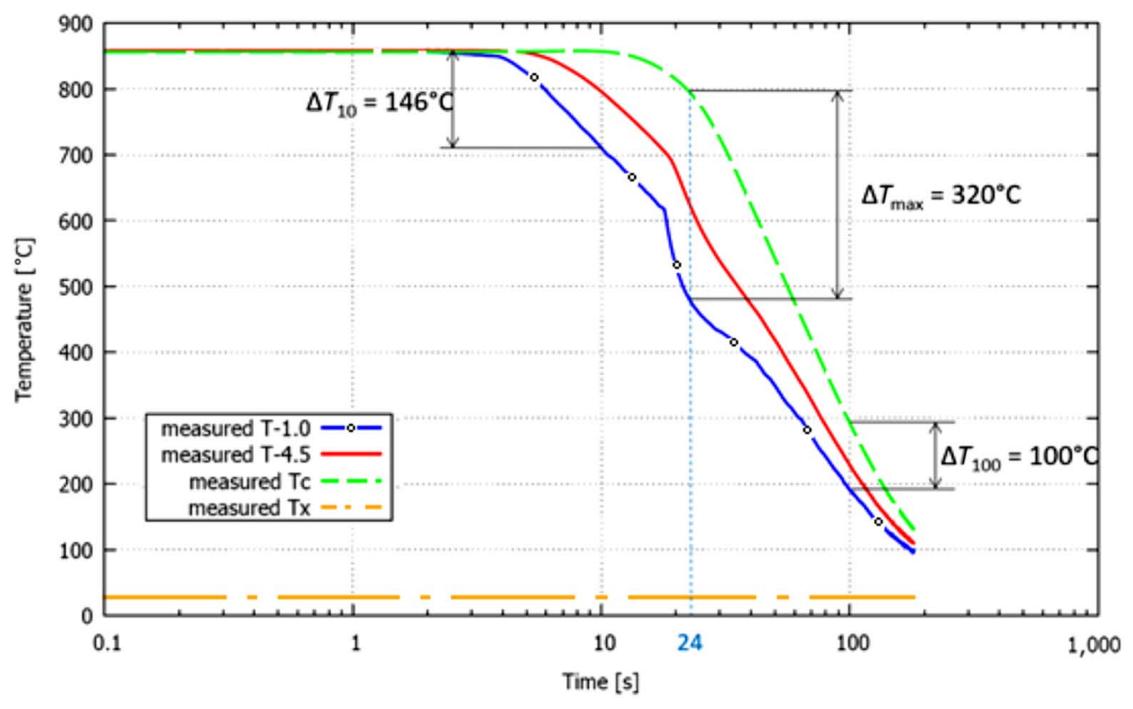

FIG. A.22 Cooling time-temperature curves of mineral oil (Kalenol 32) at $60^{\circ} \mathrm{C}$ without agitation.

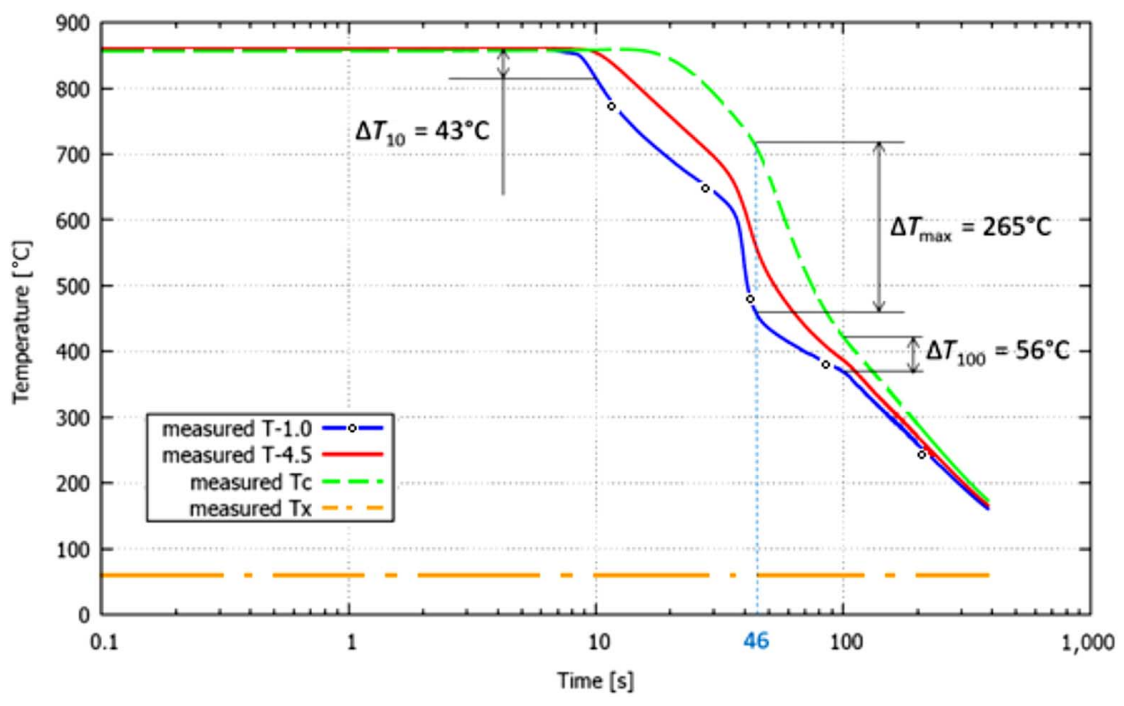


FIG. A.23 Cooling time-temperature curves of mineral oil (Kalenol 32) at $60^{\circ} \mathrm{C}$ moderate agitation.

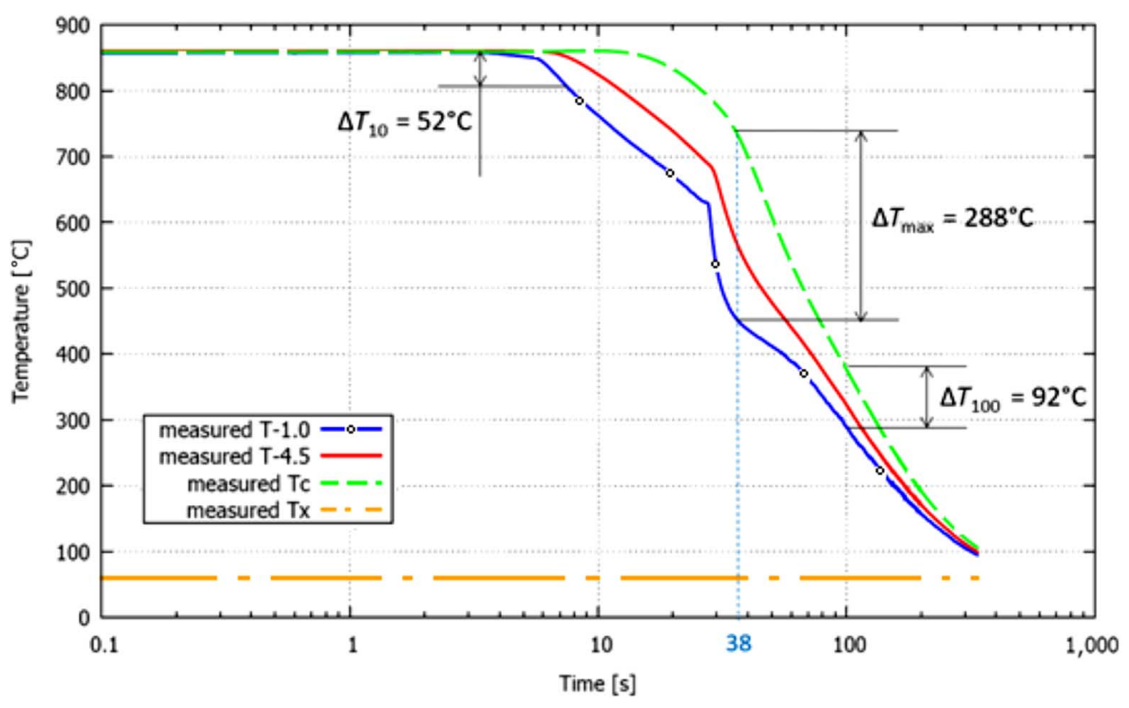

FIG. A.24 Cooling time-temperature curves of mineral oil (Kalenol 32) at $60^{\circ} \mathrm{C}$ intensive agitation.

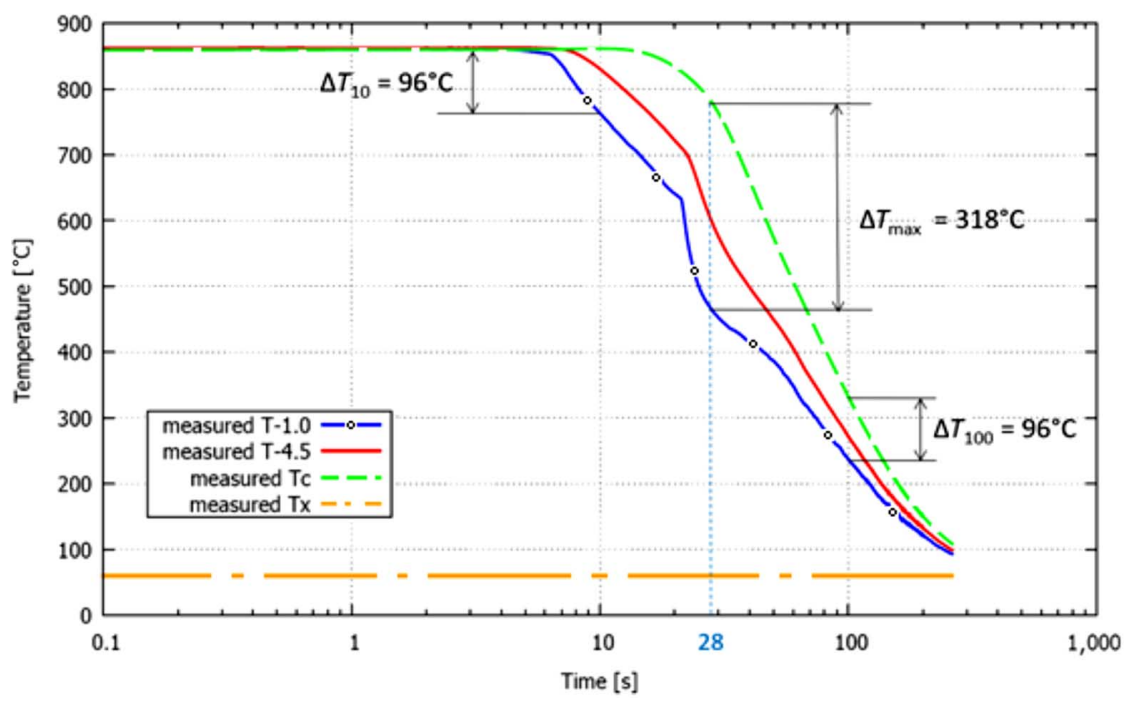

\section{References}

1. Standard Test Method for Determination of Cooling Characteristics of Quench Oils by Cooling Curve Analysis, ASTM D6200-97 (West Conshohocken, PA: ASTM International, 2001). https://doi.org/10.1520/D6200-01R17.

2. F. Mayinger, B. Liščić, H. M. Tensi, L. C. F. Canale, and G. E. Totten, "Thermo- and Fluid-Dynamic Principles of Heat Transfer During Cooling," in Quenching Theory and Technology, 2nd ed. (Boca Raton, FL: CRC Press, 2010), 129-158.

3. B. Liščić, "Measurement and Recording of Quenching Intensity in Workshop Conditions Based on Temperature Gradients," Materials Performance and Characterization 5, no. 1 (2016): 209-226, https://doi.org/10.1520/MPC20160007 
4. N. Kobasko and B. Liščić, "Liscic/Petrofer Probe to Investigate Real Industrial Hardening Processes and Some Fundamentals during Quenching of Steel Parts in Liquid Media,” EUREKA: Physics and Engineering 6, no. 6 (2017): 48-56, https://doi.org/10.21303/2461-4262.2017.00495

5. R. L. Simencio Otero, L. C. F. Canale, and G. E. Totten, "Use of Vegetable Oils and Animal Oils as Steel Quenchants: A Historical Review- 1850-2010,” Journal of ASTM International 9, no. 1 (January 2012): Paper ID JAI 103534, https://doi. org/10.1520/JAI103534

6. E. Blotière, J. Grouillet, and A. Renard, Palm Oil - The Environmental Dilemma, Report Published by Amundi Discussion Papers Series, DP-23-2017 (Paris: Amundi, 2017), 1-54.

7. O. S. Jolayemi, M. A. Ajatta, and A. A. Adegeye, "Geographical Discrimination of Palm Oils (Elaeis guineensis) Using Quality Characteristics and UV-Visible Spectroscopy,” Food Science \& Nutrition 6, no. 4 (March 2018): 773-782, https:// doi.org/10.1002/fsn3.614

8. A. Tres, C. Ruiz-Samblas, G. van der Veer, S. M. van Ruth, "Geographical Provenance of Palm Oil by Fatty Acid and Volatile Compound Fingerprinting Techniques,” Food Chemistry 137, nos. 1-4 (April 2013): 50-142, https://doi.org/10. 1016/j.foodchem.2012.09.094

9. R. Przybylski and N. A. M. Eskin, "Chapter 7 - Oil Composition and Properties," in Canola: Chemistry, Production, Processing and Utilization, J. K. Daun, N. A. M. Eskin, and D. Hickling, eds. (New York, NY: Academic Press, 2011), 163-188, https://doi.org/10.1016/C2015-0-02414-5

10. Anon, "Where is Canola Oil Produced and Used?," Futures Knowledge, 2014, https://perma.cc/AU73-59K8

11. J. McKinnon and V. Racz, "Nutritional Evaluation and Processing of Canola Screenings for Ruminants," University of Saskatchewan (February 2000): 1-82, https://perma.cc/7NK5-6FBY

12. E. C. de Souza, M. R. Fernandes, S. C. M. Augustinho, L. C. F. Canale, and G. E. Totten, "Comparison of Structure and Quenching Performance of Vegetable Oils,” Journal of ASTM International 6, no. 9 (October 2009): 1-25, https://doi.org/ 10.1520/JAI102188

13. E. C. de Souza, C. Bronzini, A. Gaston, G. S. Sarmiento, L. C. F. Canale, and G. E. Totten, "Heat Transfer Coefficient Characterization of Vegetable Oils," in 65th ABM International Congress/18th IFHTSE Congress (São Paulo, Brazilian Association of Metallurgy, Materials and Mining, 2010), 4740-4749.

14. E. C. de Souza, G. Belinato, R. L. Simencio Otero, É. C. A. Simêncio, S. C. M. Augustinho, W. Capelupi, C. Conconi, et al., “Thermal Oxidative Stability of Vegetable Oils as Metal Quenchants," Journal of ASTM International 9, no. 1 (January 2011): 1-30, https://doi.org/10.1520/JAI103817

15. G. Belinato, L. C. F. Canale, and G. E. Totten, "Effect of Antioxidants on Oxidative Stability and Quenching Performance of Soybean Oil and Palm Oil Based Quenchants,” Journal of ASTM International 8, no. 9 (October 2011): 1-24, https:// doi.org/10.1520/JAI103376

16. D. Said, G. Belinato, G. S. Sarmiento, R. L. Simencio Otero, G. E. Totten, A. Gastón, and L. C. F. Canale, "Effect of the Oxidation Stability of Soybean Oil and Palm Oil on Steel Quenching Performance," Journal of Materials Engineering and Performance 22, no. 7 (July 2013): 1929-1936, https://doi.org/10.1007/s11665-013-0560-9

17. N. I. Kobasko, A. A. Batista Jr., L. C. F. Canale, G. E. Totten, and V. V. Dobryvecher, "Cooling Capacity of Coconut, Palm and Commercial Petroleum Oil by Solving the Heat Conductivity Inverse Problem," Material Performance and Characterization 2, no. 1 (2013): 319-338, https://doi.org/10.1520/MPC20120047

18. B. Liscic, "Der Temperaturgradient auf der Oberfläche als Kenngrösse fur die reale Abschreckintensität beim Härten," Härterei-Technische Mitteilungen (HTM) 33, no. 4 (1978): 179-191.

19. Standard Test Method for Determination of Cooling Characteristics of Quenchants by Cooling Curve Analysis with Agitation (Drayton Unit), ASTM D6549-06 (West Conshohocken, PA: ASTM International, 2015). https://doi.org/ 10.1520/D6549-06R15

20. Standard Test Method for Determination of Cooling Characteristics of Quenchants by Cooling Curve Analysis with Agitation (Tensi Method), ASTM D6746-06 (West Conshohocken, PA: ASTM International, 2016). https://doi.org/ 10.1520/D6746-15

21. B. Matijevic, B. Liscic, G. E. Totten, and L. C. F. Canale, "Comparative Measurement and Evaluation of the Quenching Intensity of Palm Oil, Canola Oil and a Conventional Petroleum Oil Quenchant Based on Temperature Gradient Measurements," Materials Performance and Characterization 6, no. 5 (November 2017): 757-776, https://doi.org/10. 1520/MPC20170041

22. R. W. Wolke, "Up in Smoke," Washington Post, 1999, https://perma.cc/EYM5-4KYQ

23. L. Retlief, "Analysis of Vegetable Oils, Seeds and Beans by TGA and NMR Spectroscopy" (PhD Thesis, University of Stellenbosch, 2011).

24. E. O. Aluyor, C. E. Ozigagu, O. I. Oboh, and P. Aluyor, "Chromatographic Analysis of Vegetable Oils: A Review," Scientific Research and Essay 4, no. 4 (April 2009): 191-197.

25. P. T. Gee, "Analytical Characteristics of Crude and Refined Palm Oil and Fractions," European Journal of Lipid Science and Technology 109, no. 4 (April 2007): 373-379, https://doi.org/10.1002/ejlt.200600264 